\title{
Sisorta (Koyulhisar-Sivas) Yüksek Sülfidasyon Epitermal Altın Yatağının Jeoloji-Mineralojisi ve İzotop (O-D, S, Cu ve Ar/Ar) Jeokimyası
}

\author{
Geology-Mineralogy and Isotope (O-D, S, Cu And Ar/Ar) Geochemistry of Sisorta High Sulfi- \\ dation Epithermal Gold Deposit (Koyulhisar-Sivas)
}

\section{Çiğdem ŞAHIN DEMİR ${ }^{1}$ ve Ali UÇURUM ${ }^{1}$}

Cumhuriyet Üniversitesi, Jeoloji Mühendisliği Bölümü, 58140-SiVAS

csahin@cumhuriyet.edu.tr

\section{ÖZ}

Bu çalışma Evliya Tepe yakınında Güzelyurt köyü Sisorta bölgesindeki altın yatağının jeolojik ve

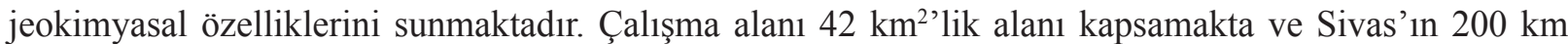
KB'da Sisorta'dadır.

Sisorta altın yatağında kükürt izotop değerleri; \%o $-0,4$ ile \%o 22,0 arasında değişmektedir. Bu sonuçlarda cevherleşmenin oluşumunda etkili olan S'ün kaynağının ilk evrelerinde hafif S izotopunun etkin olduğu daha sonraki evrelerde ise ağır $\mathrm{S}$ izotopunun etkin olduğu gözlenmektedir.

Gang ve alteasyon minerallerinde yapılan oksijen ve döteryum analizlerine göre; $\delta^{18} \mathrm{O}$ değeri \%o 7,1 ile \%o 15,6 arasında değişirken, $\delta \mathrm{D}$ değeri ise $\%$ - -77 ile $\%$ - 25,3 arasındadır. $\delta^{18} \mathrm{O}$ ve $\delta \mathrm{D}$ izotop değerleri birlikte değerlendirildiğinde meteorik sular, silikat alterasyon minerallerinin oluşumunda önemli rol oynamıştır.

Yapılan ${ }^{40} \mathrm{Ar} /{ }^{39} \mathrm{Ar}$ yaş analizleri sonucunda K-alünit minerallerinde; plato yaşı $78,85 \pm 0,94 \mathrm{My}$ ve

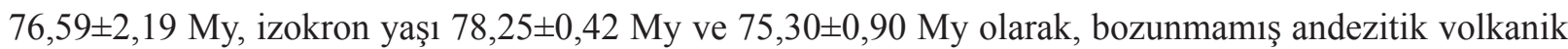
kayaçlardan ayrılan hornblend mineralinde ise plato yaşı $80,44 \pm 0,84$ My elde edilmiştir. Bu sonuçlar altın cevherleşmesinde etkin olan hidrotermal alterasyonun ana kayacın yerleşiminden 3 My sonra geliştiğini göstermektedir.

Sisorta altın yatağında bulunan bakır minerallerinde elde edilen $\%{ }^{6}{ }^{65} \mathrm{Cu}$ izotop değerleri -5.502 ile +3.032 arasında değişim göstermektedir. Intrüzyona (sistemin derin kısmı) yakın yerlerdeki bakır izotop değerleri önemli bir izotopsal değişim göstermemektedir $(\%<1)$, bunun tersine sistemin üst kesimlerinde bakır izotop değerleri geniş bir değişim göstermekte ve buda ikincil süreçlerle bakır zenginleşmesini işaret etmektedir.

Anahtar Kelimeler: Ar/Ar Yaşlandırma, Duraylı İzotop, Sisorta, Yüksek Sülfidasyon Epitermal Altın Yatağ 


\section{ABSTRACT}

This study presents geological and geochemical features of gold deposit located in Sisorta area near Evliya Tepe, Güzelyurt village. The investigation area covers $42 \mathrm{~km}^{2}$ land and located in $200 \mathrm{~km} \mathrm{NW}$ of Sivas province in Sisorta. .

$\delta{ }^{34} S \%$ isotope values are ranging from $-0,4$ and \%o \%o 22, in Sisorta gold deposit. At the early stage of mineralization $S$ isotope value number is light and later $S$ isotope value shows heavy numbers. This is indicating that the $S$ isotope was originated from magma and changed due to temperature variations in the last stages of the hydrothermal process.

$\delta^{18} \mathrm{O}$ isotope values of gangue minerals are ranging from; \%o 7,1 and \%o 15, 6 however, $\delta D$ value is ranging from \%o -77 to \%o-25,3 Combining $\delta^{18} O$ with $\delta D$ from Sisorta samples, demonstrates meteoric waters were important in the formation of the alteration silicate minerals analyzed. This is common in high sulfidation silicate alteration minerals.

${ }^{40} \mathrm{Ar} /{ }^{39} \mathrm{Ar}$ age dating is ranging from $78,85 \pm 0,94 \mathrm{Ma}$ and $76,59 \pm 2,19 \mathrm{Ma}$ as a plateau age and 78,25 $\pm 0,42$

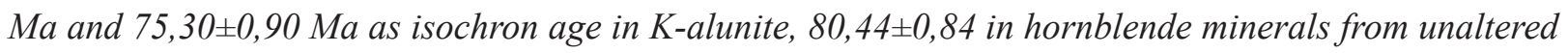
andesitic volcanic rocks. This shows that hydrothermal gold mineralization is deposited 3 Ma later than the volcanic host rock eruption.

$\delta{ }^{65} \mathrm{Cu} \%$ values from copper-bearing minerals associated with Sisorta gold deposits are ranging from $-5.502 \%$ o to $+3.032 \%$. The copper isotope values closest to the intrusions (deepest part of the system) do not show significant copper isotope variations (<1 per mil), in contrast the upper parts of the system show large copper isotope variations and indicate enrichment of copper due to supergene processes.

Key Words: Ar/Ar Dating, High Sulphidation Epithermal Gold Deposit, Sisorta, Stable Isotopes

\section{GíRíş}

İnceleme alanı, Sivas il merkezinin yaklaşık $200 \mathrm{~km}$ kuzey doğusunda Sisorta Bölgesinde yer alan Güzelyurt Köyü, Evliya Tepe civarını kapsamaktadır ve 1/25000'lik Giresun H-40 a1 paftasında yaklaşık $42 \mathrm{~km}^{2}$ 'lik bir alanı teşkil etmektedir (Şekil 1).

$\mathrm{Bu}$ çalışma ile Sisorta altın yatağının mineralojik, petrografik jeokimyasal özelliklerinin incelenmesi amaçlanmıştır.

$\mathrm{Bu}$ kapsamda; petrografik amaçlı hazırlanan ince kesit ve parlatma bloklarının incelenmesiyle inceleme alanındaki alterasyon türleri ve cevher mineral parajenezi belirlenmiştir. Alterasyon minerali olan K-Alünit ve yan kayaçtan ayrılan hornblend minerallerinde $\mathrm{Ar} / \mathrm{Ar}$ yaş analizi ile alterasyon ve cevherleşmenin yaşı hakkında çıkarımlar yapılmıştır. Kuvars ve alünit minerallerinde yapılan $\mathrm{O}$ ve $\mathrm{D}$ izotop analizleri ile cevherleşmede etkili olan hidrotermal suyun kökeni belirlenmiştir. Pirit, kalkopirit, barit ve alünit minerallerinde yapılan $\mathrm{S}$ izotop analizi ile cevherleşmeye eşlik eden S'ün kaynağı ve kökeni belirlenmiştir. Cevher minerallerinde yapılan $\mathrm{Cu}$ izotop analizi ile cevherleşmeye eşlik eden bakırın kaynağı belirlenerek derinlerde bulunması olası olan porfiri sistem için çıkarımlara gidilmiştir. 


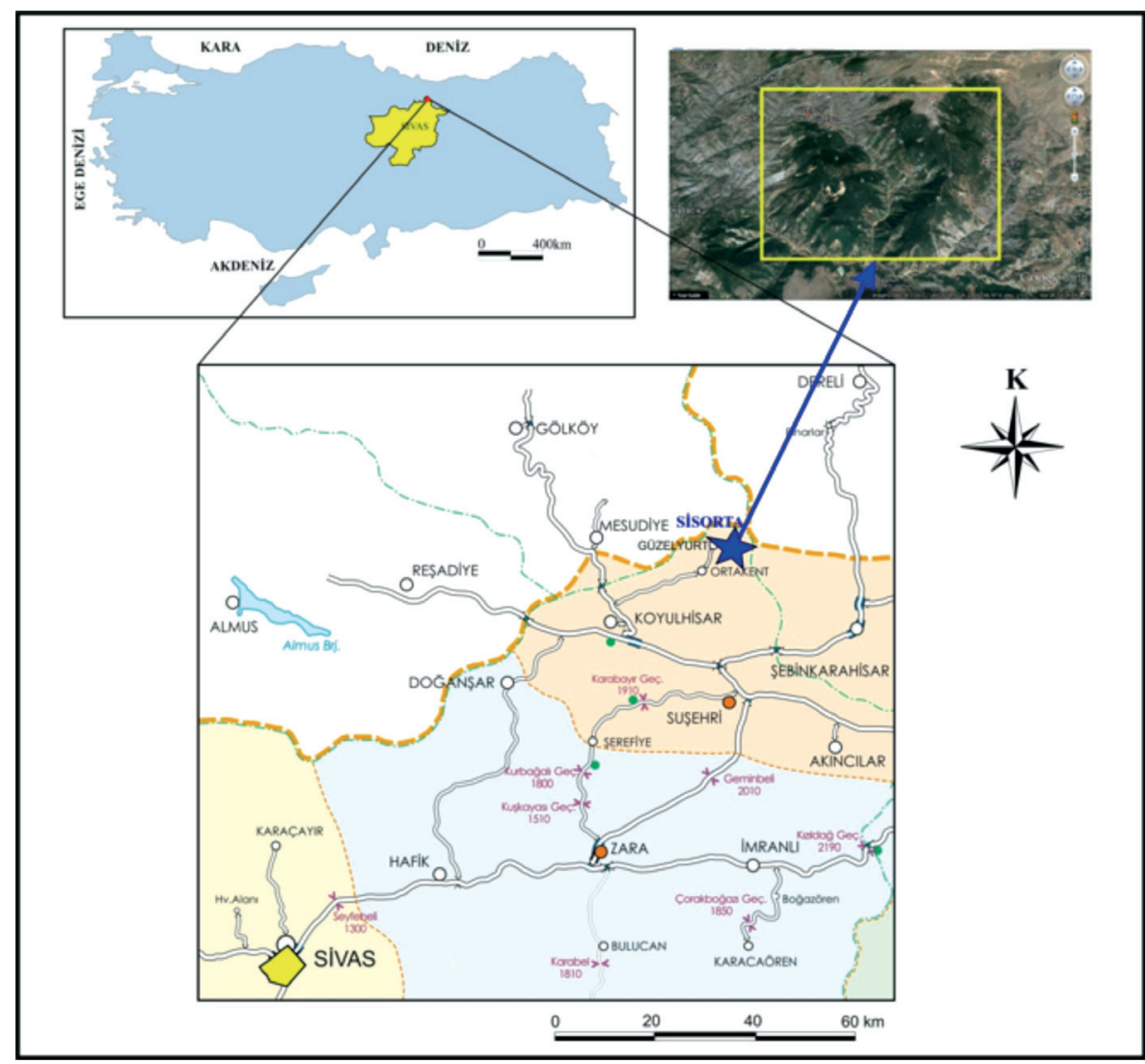

Şekil 1. İnceleme alanının yer bulduru haritası.

Figure 1. Lacation map of investigation area

\section{GENEL JEOLOJI}

İnceleme alanının temelini Üst Kretase (Üst Santoniyen-Alt Maastrihtiyen) yaşlı andezitik aglomera ve tüfler oluşturmaktadır. Aglomeraların üzerine Üst Kretase (Üst Maastrihtiyen) yaşlı andezitik lavlar gelmektedir. Üst Kretase yaşlı plütonik kayaçlar bu volkanik kayaçları kesmektedir. Tüm bu birimler Kuvaterner yaşlı alüvyonlar ile açısal uyumsuzluk ile örtülmektedir (Şekil 2, 3).

\section{Andezitik Aglomera ve Tüfler}

$\mathrm{Bu}$ birim, inceleme alanının kuzeybatısında Güzelyurt Köyü, doğusunda Kurşunlu Köyü ve Gümüşlü Köyü, güneybatısında da Acıdere Mahallesi civarında yaygın olarak gözlenmektedir.

Andezitik aglomeralar; inceleme alanında gözlenen birimlerin tabanını oluşturmaktadır. Topoğrafyanın sarp olmadığı daha yumuşak düzlük alanlarda yayılım göstermektedirler. Genellikle tabakalanmasız olmakla beraber, yer yer çok kalın tabakalanma da gösterebilmektedir. Yer yer iyi gelişmiş akma dokusu gözlenmektedir. Aglomeralar $\mathrm{KD}$ ve $\mathrm{KB}$ doğrultulu gelişmiş çatlaklar içermektedir. Aglomeralar içindeki çatlaklarda ikincil kalsit, silis, hematit ve limonit dolguları gözlenmektedir. 


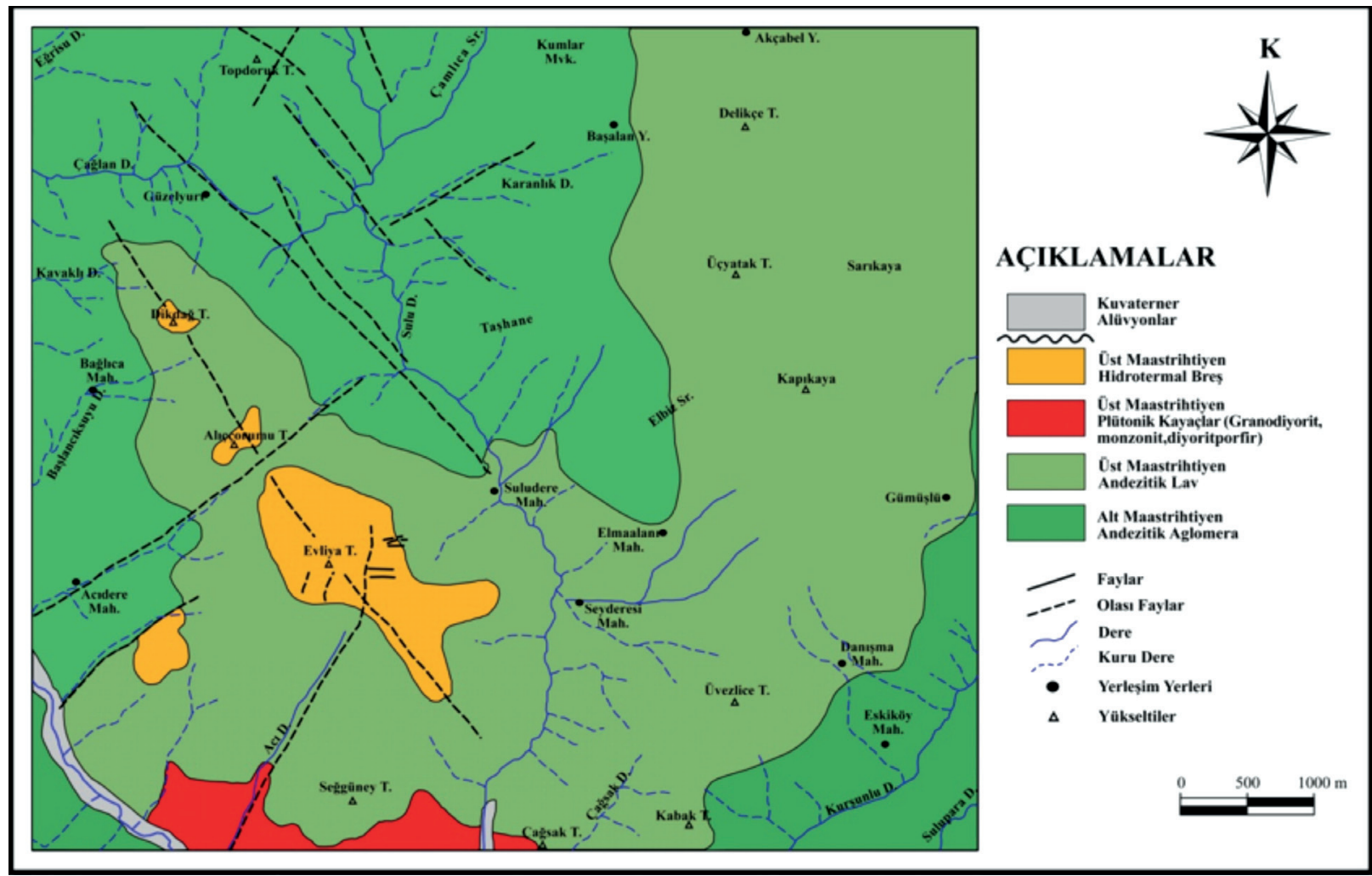

Şekil 2. İnceleme alanının jeoloji haritası (Şahin Demir, 2015).

Figure 2. Geological map of investigation area.

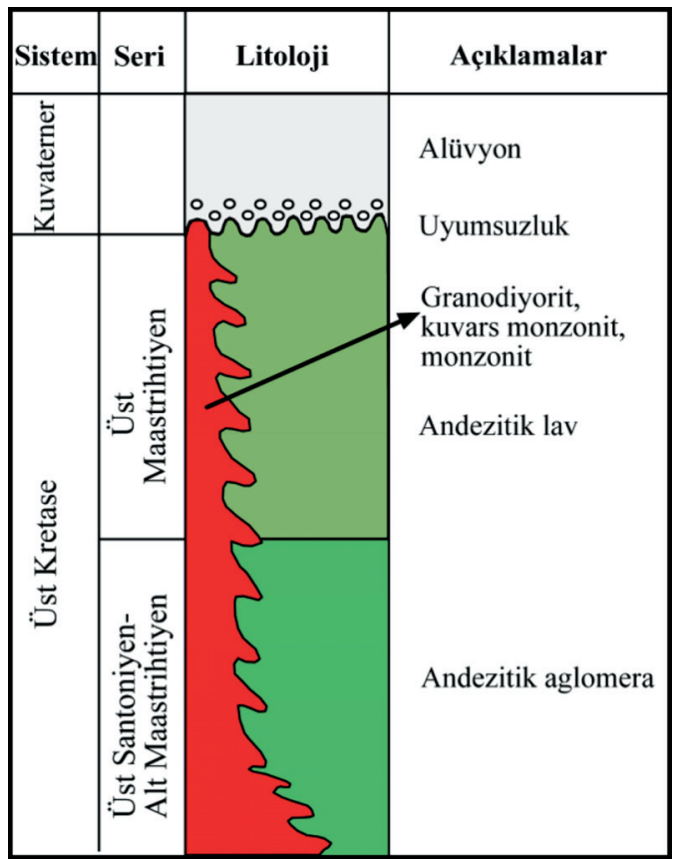

Şekil 3. Çalışma alanının genelleştirilmiş stratigrafik kolon kesiti, ölçeksiz (Şahin Demir, 2015).

Figure 3. Columnar section of study area, not to scale. 
Aglomeralar; koyu gri, kırmızıms1, kahverengimsi, siyahımsı ve yeşilimsi renklerde, ince taneli olarak gözlenmektedir. Aglomera içindeki parçaların boyutları 4-60 $\mathrm{cm}$ arasında değişmektedir. Parçalar çoğunlukla andezitik, nadiren de bazaltik özelliktedir. Aglomeraları oluşturan parçalar birbirleriyle genellikle tüf ve daha az gözlenen karbonattan oluşan bir matriks ile tutturulmuştur. Aglomeraların parçaları çoğunlukla yarı köşeli - yarı yuvarlak olarak gözlenmektedir (Şekil 4a).

\section{Andezitik Lavlar}

$\mathrm{Bu}$ birim inceleme alanının kuzeydoğusundan güneydoğusuna doğru uzanan Akçabel Yayla, Delikçe Tepe, Üç Yatak Tepe, Kapıkaya, Kabak Tepe ve çalışma alanının yaklaşık orta kesimlerinde yer alan Sayderesi Mahallesi, Elma
Alanı Mahallesi, Suludere Mahallesi ve Evliya Tepe çevresinde yaygıı bir şekilde gözlenmektedir.

Andezitik lavlar çalışma alanının temelini oluşturan aglomeraların üzerine uyumlu olarak gelmektedir (Şekil 4b). İnceleme alanının güneyinde, plütonik kayaçlarca kesilmektedirler.

$\mathrm{Bu}$ birim, inceleme alanında sarp bir topoğrafya oluşturur. Genellikle siyahımsı, grimsi, yeşilimsi ve kahverengimsi renkte gözlenmektedir. Bol miktarda çatlaklı ve kırıklı bir yapıya sahiptir. Andezitik lavlar içerisindeki bu çatlaklar içerisinde, silis, kalsit dolguları gözlenmektedir. Yüksek sülfürlü epitermal $\mathrm{Au}-\mathrm{Cu}$ cevherleşmesi, bu andezitik lavlarla ilişkili olarak gelişmektedir.

Andezitik lavlar, inceleme alanında çoğunlukla hidrotermal alterasyona uğramış olarak gözlenmektedir.
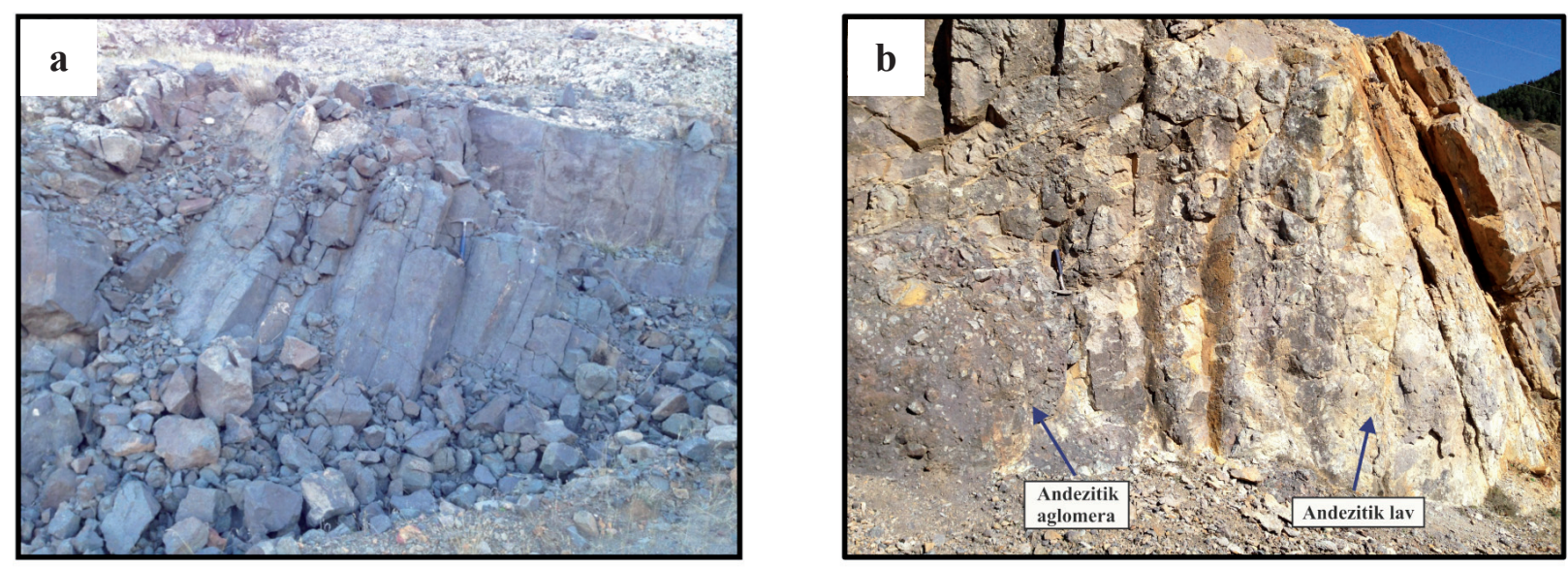

Şekil 4. a) Bağlıca Mahallesi civarındaki andezitik lavların genel görünümü, b) Bağlıca Mahallesi yakınlarında andezitik aglomeralar ile andezitik lavların sınır ilişkisi.

Figure 4. a) Field view of andesitic lavas near Baglica area b) Field view of boundary between andesitic agglomerate and lavas near Baglica district. 


\section{Plütonik Kayaçlar}

Bu birim inceleme alanı içerisinde Evliya Tepe'nin güneyinde bulunan Seğgüney Tepe ve Teğil Tepe'nin güney ve güneydoğusu ile Melet Çayı arası boyunca yaygın bir şekilde gözlenmektedir .

İnceleme alanında Üst Santoniyen-Alt Maastrihtiyen yaşlı andezitik aglomera ve Üst Maastrihtiyen yaşlı andezitik lavları kesen plütonik kayaçların yerleşme yaşları, Üst Maastrihtiyendir (Bedi, 1998).

Plütonik kayaçlar, inceleme alanında bulunan andezitik aglomeraları ve andezitik lavları kesmektedir. Yer yer kırıklı ve çatlaklı yapıda olup, eklem düzlemleri çok iyi gelişmiştir. Ayrışma rengi, açık gri, kirli sarı, açık kahverengimsi, pembemsi renk tonlarında, taze yüzeyleri ise kırmızımsı, pembemsi ve açık gri renk tonlarındadır. Makro düzeyde, feldispat mineralleri, kuvars, biyotit ve turmalin mineralleri ayırt edilebilmektedir. Ayrıca, plütonikler içerisinde kalkopirit ve pirit cevherleşmesi de gelişmiştir.

Seğgüney Tepe güneyi ve MENKA işletmesi arasında kalan plütonik kayaçlarda yer yer arjilik alterasyon gelişmiştir. Burada kayaçlar kirli sarımsı, kahverengimsi renkte gözlenir.

Petrografik incelemeler sonucu, plütonik kayaçlar, granodiyorit, kuvars monzonit, monzonit ve diyorit porfir olarak tanımlanmışlardır.

\section{Hidrotermal Breşler}

Çalışma alanında, Evliya Tepe, Aliçorumu Tepe, Dikdağ Tepe, Delikçe Tepe'de yüzeylenmektedirler.

Breşler; grimsi, beyazımsı, kahverengimsi, sarımsı renklerde gözlenmektedir. İçerisinde taneler kayaç ve silika parçalarından oluşmaktadır. Silika parçaları, birkaç mm ile $5 \mathrm{~cm}$ arasındadır. Kayaç parçaları ise, yarı yuvarlakyarı köşeli olup boyutları çoğunlukla 1-10 cm, nadiren 10-20 cm arasında değişmektedir.

Breşler kırıklı, çatlaklı ve boşluklu yapıya sahiptir. Breşlerde; barit damarları ve silis damarları gelişmiştir. Barit damarları Evliya Tepe'de oldukça yaygın olarak gözlenmektedir.

İnceleme alanında gözlenen bu hidrotermal breşler literatürdeki (Lawlees ve White, 1990; Jebrak, 1997; Corbett ve Leach, 1998; Tamas ve Milesi, 2002; 2003; Ollier, 2007) benzerleri gibi çözelti kökenli "hidrolik breş" şeklinde tanımlanmıştır.

\section{ALTERASYON MINERALOJISİ VE PETROGRAFISI}

İnceleme alanında yer alan Evliya Tepe, Alıççorumu Tepe ve Dikdağ'1 içerisine alan bölgede Euroasia Madencilik Ltd. Şti. ve Chesser Arama Ltd. Şti. tarafindan yapılan sondajlardan alınan numunelerde, PIMA (Portable Infrared Mineral Analyzer) yöntemi kullanılarak alterasyon mineralleri tanımlanmıştır. Elde edilen bu veriler ve saha gözlemleri ile birlikte Evliya Tepe ve civarının 1/5000 ölçekli alterasyon haritası yapılmıştır (Şekil 5) (Chadwick, 2005). Yapılan çalışmalara göre, Evliya Tepe ve civarında alterasyon, epitermal ve mezotermal olmak üzere iki grupta ele alınmış ve arjilik, ileri arjilik, ileri arjilik yüksek sülfür, pirofillitik, fillik ve silisleşme türü alterasyonlar belirlenmiştir (Yetkin, 2009).

Evliya Tepe civarındaki karotörneklerinde yapılan PIMA sonuçlarına ilaveten, inceleme alanından alınan yüzey ve karot örneklerinde yapılan petrografik incelemeler, X-1şınları analizi ve saha gözlemleri ile birlikte, inceleme alanında; pirofillitik, arjilik, ileri arjilik, boşluklu silika ve silisleşme türü alterasyonlar tanımlanmıştır. 


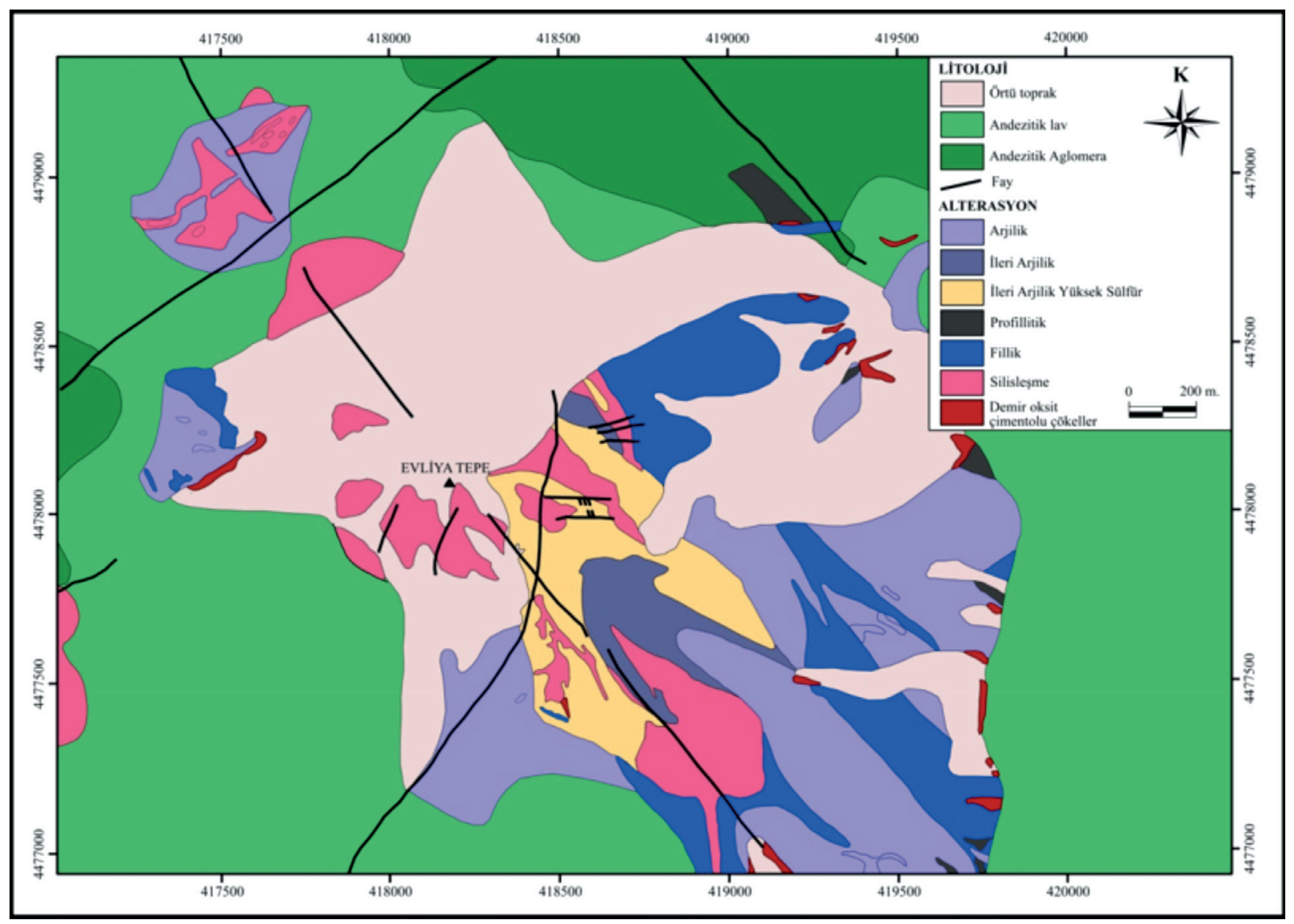

Şekil 5. Evliya Tepe ve civarının 1/5000 ölçekli alterasyon haritası.

Figure 5. 1/5000 scale alteration map nearby Evliya Tepe.

\section{Pirofilitik Alterasyon}

İnceleme alanında en diş zonda gözlenen alterasyondur ve arjilik alterasyonu çevreler. Çoğunlukla daha düşük kotlarda geniş bir yayılım göstermektedir.

Güzelyurt Köyü civarı ve kuzeyinde Topdoruk Tepe civarında, ayrıca Bağlıca Mah. civarında andezitik aglomeralarda yaygın olarak veya sacınımlı ağsı şekillerde gözlenmektedir. $\mathrm{Bu}$ alterasyon Evliya Tepe'de aşınma, kenar k1sımlarda örtü nedeniyle çok az gözlenmektedir. Mineral parajenezini, kalsit, klorit, epidot, albit ve kil mineralleri oluşturmaktadır. El örneği düzeyinde kloritleşmeler ve epidotlaşmalar belirgindir (Şekil 6a,b).

İnce kesitte incelendiğinde, hornblend fenokristallerinde yaygın olarak epidotlaşma ve karbonatlaşma, plajiyoklaz fenokristallerinde yaygın karbonatlaşma gelişirken, hamurdan itibaren çoğunlukla kloritleşmeler geliştiği gözlenmiştir (Şekil 9a). 

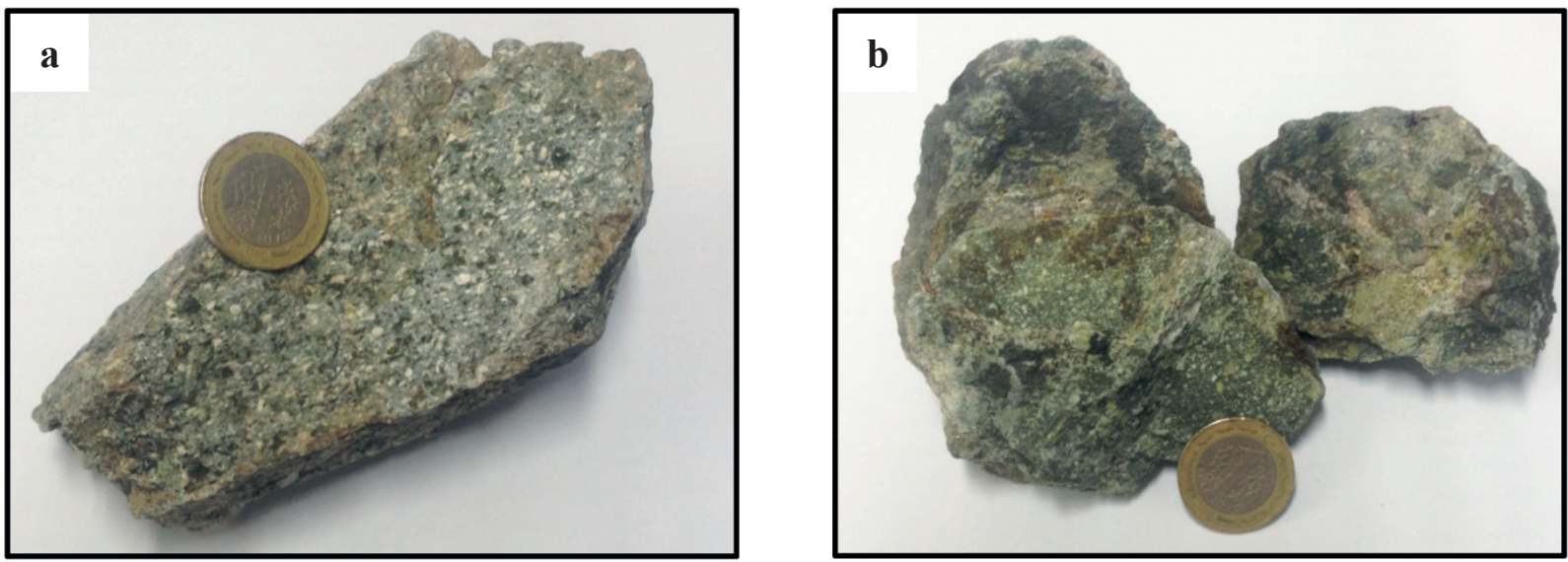

Şekil 6. El örneği düzeyinde pirofillitik alterasyonun görünümü a) SIS-1031, b) SIS-1130).

Figure 6. The appearance of propylitic alteration on hand specimens a) SIS-1031, b) SIS-1130).

\section{Arjilik Alterasyon}

Orta derecede arjilik alterasyon olarakta adlandırılır. Ana mineralleri kaolinit/dikit montmorillonit, illit ve smektittir. Daha az oranlarda kuvars ve pirit minerali içermektedirler. Yüksek sülfürlü epitermal sistemlerde ileri arjilik alterasyon ile pirofillitik alterasyon arasında geçiş zonu olarak gözlenir.

İnceleme alanında Evliya Tepe'nin batısında yeralan Kışladere ve GB'sında yer alan Acı Dere yamaçlarında geniş yüzleklerde görülmektedir (Şekil 7a). Yüzeyde oldukça yoğun bir kil/beyaz mika alterasyonu ile karakterize edilir ve yüzeyde daha fazla beyazlaşma göstermektedir. Yoğun killeşmeye maruz kalarak dayanımı düşen volkanik kayaçlar, Evliya Tepe'de KD doğrultulu fay sistemine bağlı olarak oldukça dik heyelanlar oluşturmuşlardir.

Ayrıca, Evliya Tepe'nin güney doğu eteklerindede dahaazyoğun olarakgözlenmektedir. Bunun yanı sıra, inceleme alanının güney sınırında yer alan plütonik kayaçlarda da yer yer arjilik alterasyon gözlenmektedir (Şekil 7b).

Optik mikroskop incelemelerine göre, andezitik volkanik kayaçlarda plajiyoklaz mineralleri kaolinit ve illit mineraline dönüşmektedir Ayrıca, volkan camından itibaren de kaolinit mineraline dönüşüm gözlenmektedir (Şekil 9 b).

\section{İleri Arjilik Alterasyon}

İleri arjilik alterasyonu asit sülfat alterasyonu olarakta bilinir. Ana mineralleri kuvars, kaolinit / dikit ve alünittir. Değişen oranlarda diaspor, pirofillit rutil, zunyit, alüminofosfat ve sülfatlar, kükürt, pirit ve hematit minerallerini de içerebilirler. Bazı porfiri sistemlerin üst kısımlarında (şapka-kaya) geniş yayılımlı zonlar şeklinde ve ayrıca yüksek sülfürlü epitermal yatakların etrafinda alterasyon haleleri şeklinde daha sinırlı olarak bulunurlar.

İnceleme alanında Evliya Tepe'nin üst kotlarında silis şapka zonun alt kesimlerinde gözlenmektedir. Yüzleklerde gri-beyaz, pembemsi, soluk kahverengi renk göstermektedir. Kayaç alünitce zengin bir alterasyon gösterdiğinde pembemsi-soluk kahverengi renk sunmaktadir (Şekil 8a).

Petrografik incelemeler neticesinde kuvars-alünit, kuvars- kaolinit, kuvars-pirofillitdiaspor birlikteliği ayırt edilmiştir (Şekil 9c, d). 

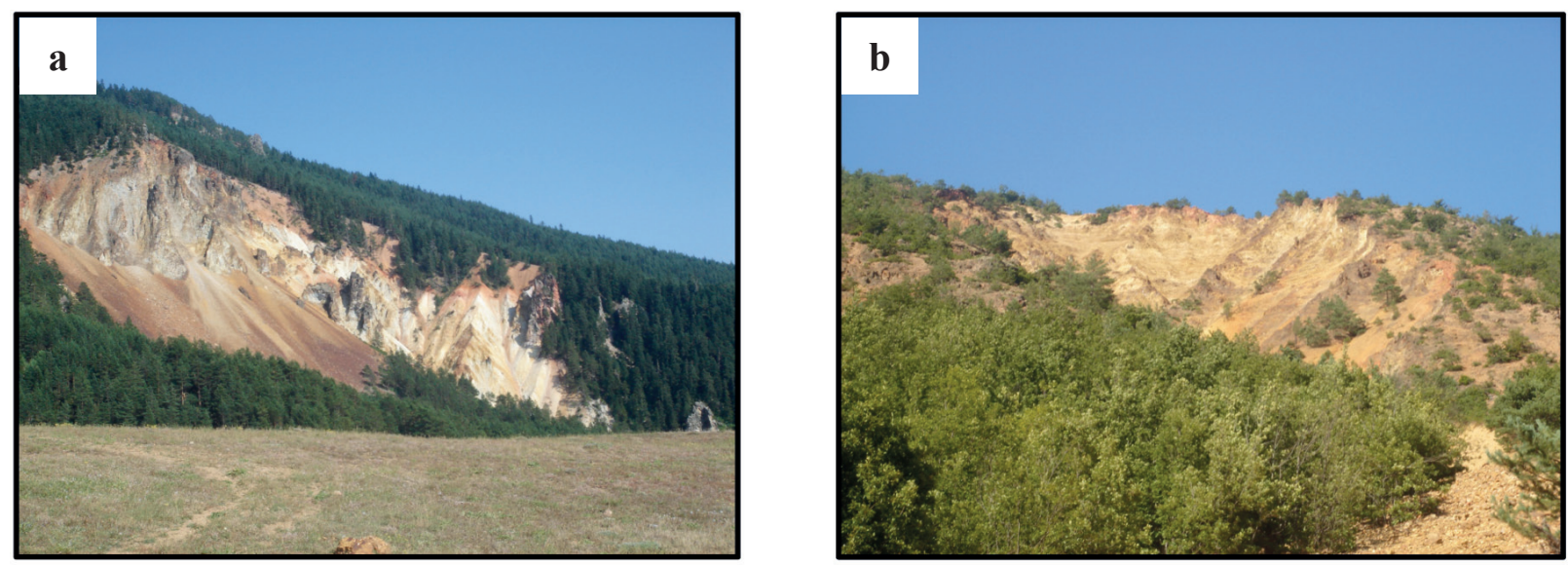

Şekil 7. a) Kışladere'de arjilik alterasyonun genel görünümü, KD’ya bakış, b) Granodiyoritik kayaçlarda arjilik alterasyonun genel görünümü, KD'ya bakış.

Figure 7. a) field view of argillic alteration in Kisladere, looking $N E$, b) field view of argillic alteration from granodiorites, looking NE.

\section{Boşluklu (vuggy) Silika}

Boşluklu silika alterasyonu çok düşük pH'lı sulu sıvıların veya buharların kayaç ile etkileşimi yoluyla oluşmaktadır. Bu sıvılar, kayaçtaki $\mathrm{SiO}_{2}$ (kuvars) ve $\mathrm{TiO}_{2}$ (rutil) hariç tüm bileşenleri etkin bir şekilde çıkarırken geriye artık boşluklu silika birakırlar.

İnceleme alanında boşluklu silika Evliya Tepe'de gözlenmektedir (Şekil 8b). Boşluklu silika andezitlerdeki çözünmüş plajiyoklaz ve mafik mineral (özellikle hornblend) fenokristallerinin oluşturduğu boşluğa silika çökelmesiyle oluşmaktadır ve \% 90'dan fazla kuvars içeriği ile tanımlanmaktadır. Boşluklu silika yüksek sülfidasyon epitermal sistemler için karakteristiktir.
İnce kesitte kuvarslar yoğun bir mozaik doku oluşturmaktadır. Boşluklarda özşekilli kuvars mineralleri dizilidir (Şekil 9e). Bazı kuvarsların düzensiz rutil, pirit veya diğer sülfür mineral topları içerdiği gözlenmektedir. Bazı durumlarda kuvarslar, ikincil kuvars, alünit ve barit damarları ile kesilmektedir.

Alterasyon zonunun kenarlarından itibaren, boşluklu silika, dereceli olarak kuvarsalünit ve kuvars-kaolinit (veya daha yüksek sıcaklıklarda pirofillite) alterasyonuna geçiş gösterir. $\mathrm{Bu}$ değişim, düşük $\mathrm{pH}^{\prime} \mathrm{l}_{1}$ sıvıların yan kayaç ile etkileşimi sırasında kısmi olarak nötralleştiğini göstermektedir. Boşluklu silika alterasyonu birçok yüksek sülfürlü $\mathrm{Au}-\mathrm{Cu}$ yataklarının çekirdeğinde, bazı porfiri yatakların üst kısımlarında ve bazı strato-volkanların aşınmış merkezlerinde oluşurlar. 

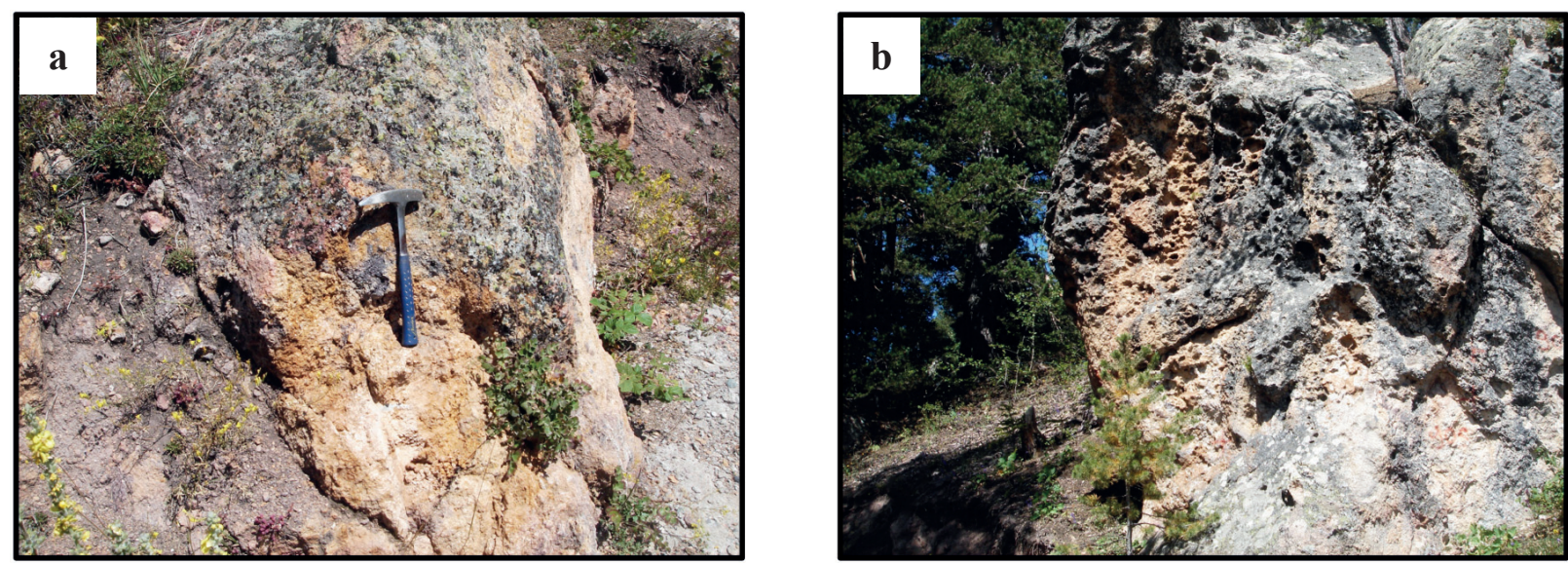

Şekil 8. a) Evliya Tepe civarında ileri arjilik alterasyonun yakın görünümü SISY-47 örneğinin alındığı lokasyon, b) Evliya Tepe'nin altındaki boşluklu (vuggy) silikanın görünümü.

Figure 8. a) close up field view of advance argillic alteration, location fort he sample \# SISY-47, b) field view of vuggy silica beneath Evliya Tepe.

\section{Silisleșme}

İnceleme alanında silisleşme yoğun olarak Evliya Tepe'de gözlenmektedir. Evliya Tepe'nin zirvesi sert ve dayanımlı kuvarsca zengin silis şapka olarak tanımlanmıştır. $\mathrm{Bu}$ silis şapkanın oluşumunda Evliya Tepe'nin kuzeybatısı ve güneydoğusundaki $\mathrm{KB}$ ve KD doğrultulu faylanmalar etkili olmuştur. Bu yüzden, bu faylanmaların kesişimi, cevherleşmeyi kuşatan silikayla ilişkili epitermal sistem için uygun yapısal koşullar sunmaktadır (Chadwick, 2005). Silisleşme nispeten daha az olarak sırasıyla Üçyatak Tepe, Kapıkaya, Sarıkaya, Delikçe Tepe, Alıççorumu Tepe, Dikdağ Tepe ve Kabak Tepe'de andezitik lavlarda ve hidrotermal breşlerde gözlenmektedir. Genel anlamda sahada 1950m.'nin üzerindeki kotlarda silisleşme gözlenmeye başlamıştır.

Kayaçlara hidrotermal kökenli veya artık magmatik çözeltilerle silis getirimi ile gerçekleşen bir süreçtir. Bazı volkanik kayaçların boşlukları ve kırık - çatlakları boyunca ikincil kuvars, kalsedon veya opal gibi silis minerallerinin yerleştiği yaygın olarak gözlenmektedir.
Petrografik incelemelere göre hidrotermal kuvarslar erken evre (boşluklu kuvars) ve geç evre (silisleşme) olmak üzere iki şekilde oluşmuşlardır. Boşluklu kuvarslar daha ince taneli iken geç evredeki kuvarslar orta-iri taneli bantlı, tarak yapısı şeklinde gözlenmektedir (Şekil 9f).

\section{CEVHER MINERALOJISII VE PETROGRAFISII}

Cevher petrografisi incelemeleri sonucunda; pirit, kalkopirit, pirotin, tetraedrit-tennantit, kovelin, kalkosin, bornit, enarjit, dijenit, sfalerit, manyetit, hematit, götit mineralleri tanımlanmıştır.

Piritler, parlatma bloklarının çoğunda yaygın olarak gözlenmiştir. Rengi beyazımsı açık sarıdır, yansıması yüksektir. Galenit ve kalkopirit minerallerinin yansımasından daha yüksektir. Çoğunlukla izotrop bir mineraldir, ancak çoğu pirit sarımsı-yeşilimsi tonlarda zayıf bir anizotropi gösterirler. Çoğunlukla özşekilli yarıözşekilli kristaller halinde gözlense de bazı kesitlerde piritler kolloform yap1 ve kabuk (shell) doku göstermektedirler. 
Kalkopirit minerali daha nadir olarak gözlenmektedir. Parlak sarı renkte, yansıması yüksek bir mineraldir ancak piritin yansımasından düşüktür. Anizotropisi zayıf çok zayıftır, sarıkahverengi, mavimsi gri veya yeşilimsi gri tonlar gösterir. İncelemelerde pirit ve sfalerit mineralleri içerisinde kapanım şeklinde veya bornit ile birlikte gözlenmektedir.

Bornit minerali pembe-kahverengi renktedir ve anizotropisi zayıftır. Sıklıkla kahverengi-gri-pembe kahverengi renkli karakteristik olmayan tonlarda zayıf bir anizotropi gösterirler. İncelemeler de bornit mineralleri kalkosin minerallerine dönüşürken, kalkosinlerde kenarlarından itibaren kovelin minerallerine dönüşmüştür (Şekil 10a).

Kovelin minerali mavi renklidir ve koyu mavi- mavimsi beyaz renk aralığında pleokroyizma gösterir. Turuncu ve turuncukahverengi renkte oldukça kuvvetli anizotropi göstermektedir. Bornit, kalkopirit, kalkosin ve dijenit mineralleri ile beraber gözlenmektedir. Piritlerin kenarlarından itibaren koveline dönüşümler gözlenmiştir (Şekil 10b).

Kalkosin mavi gölgeli beyaz, gribeyaz renktedir. Yansıması tetrahedrit-tennantit minerallerine benzer orta derecelidir, dijenit mineralinin yansımasından biraz daha yüksektir. Anizotropisi zayif, fakat belirgindir turuncu kahverengi veya koyu yeşil tonlarda gözlenir. Bornit, kalkopirit ve dijenit mineralleri ile beraber çoğunlukla lameller şeklinde gözlenmiştir (Şekil 10b).

Dijenit minerali, mavimsi renkte, izotroptur. Yansıması ortadır, tetraedrit-tennantit mineralinin yansımasından biraz daha düşüktür. Dilinimleri oldukça belirgindir. Sıklıkla kalkosin veya kovelin mineralleri ile girintili şekilde oluşur ve birincil olarak oluşur (Şekil 10b).
Enarjit minerali açık pembe-kahverengi renktedir. Anizotropisi oldukça yüksektir. Turuncu tonlu sarı-kahverengiden, yeşilimsi tonların olduğu renklere değişen oldukça renkli bir anizotropi gösterir. Yansıması tetrahedrit-tennantit mineralininyansımasından birazdaha düşük, bornit mineralinin yansımasından oldukça yüksektir. Enarjit minerali çoğunlukla pirit ile kenetli, yer yer de serbest şekilde izlenmektedir. Pirit, enarjit, kovelin birlikteliğine parlatma bloklarında sıklıkla rastlanmıştır. Enarjit minerali kenarlarından itibaren kovelin mineraline dönüşmektedir. $\mathrm{Bu}$ dönüşüm çok yüksek sülfidasyon düzeyine geçişi işaret eder (Şekil 10c). Bazı örneklerde de enarjit minerali tennantit minerali ile birlikte (iç içe) gelişmiştir. Her iki mineral de yüksek sülfidasyon düzeyini yansıtır (Şekil 10d).

Tennantit-Tetrahedrit mineralleri katı karışım serisi ürünleridir. Tetrahedrit antimon içerikli bakır sülfür, tennantit arsenik içerikli bakır sülfür mineralidir. Tetrahedrit kahverengimsi gri renkli, izotrop bir mineraldir. Tennantit minerali gri-beyaz renktedir ve içerisinde yeşilimsi tonda gölgeler gözlenir. Galenit ile karşılaştırıldığında yeşilimsi bu tonlar ile belirgin şekilde ayırt edilir. Yansıması ortadır ve galenitin yansımasından daha düşüktür. İzotrop bir mineraldir. Sık olmamakla beraber kırmızı iç yansıması tipiktir.

Pirotinler açık kahverengi renktedir, anizotropisi güçlü ancak çok renkli değildir, sarımsı-gri-kahverengimsi gri tonlarındadır. Pirotin minerali kalkopirit minerali ile birlikte pirit minerali içerisinde kapanım halinde gözlenmiştir. $\mathrm{Bu}$ şekilde iki fazlı kapanımlar tek fazlı kapanımlara göre daha nadir gözlenir. Pirotin-kalkopirit kapanımı ortaç bileşimdeki katı çözeltinin karışmamasıyla oluşmuştur. Erken dönem düşük-orta sülfidasyon düzeyini yansıtır ve porfiri sisteme olan yakınlığ $\breve{1}_{1}$ belirtmesi bakımından önemlidir (Şekil 10e). 

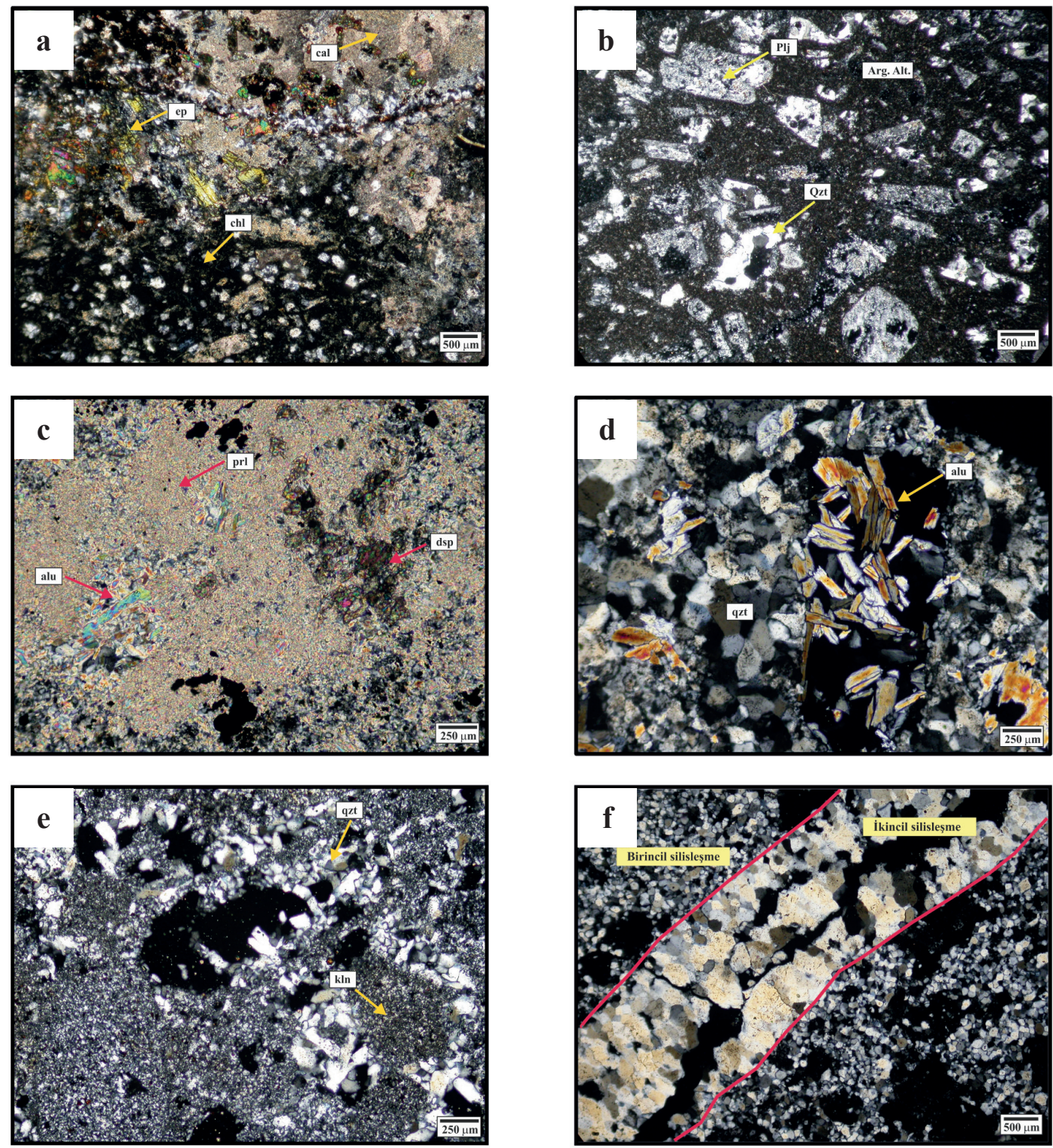

Şekil 9. Çalışma alanında gözlenen yaygın bazı alterasyon türlerinin mikrofotoğrafları: a) Pirofillitik alterasyon (SIS-1130, 5X, ÇN), b) Andezitik lavlarda arjilik alterasyon (SIS-1125, 5X, ÇN), c) Pirofillitik matriks içinde alünit kristalleri ve düzensiz şekilli diaspor minerali (SIS-48/90928, 10X, ÇN), d) Boşlukları dolduran özşekilli alünit kristalleri (SIS-1014, 10X, ÇN), e) Boşluklu (vuggy) silika (SISY-23, 10X, ÇN), f) Erken evre silisleşme (ince taneli), geç evre silisleşme (iri taneli), (SISY-67, 5X, ÇN). (ÇN:çift nikol, Arg.Alt: arjilik alterasyon, plj:plajiyoklaz, ep: epidot, cal: kalsit, chl: klorit, ep: epidot, alu: alünit, qzt: kuvars, dsp: diaspor, prl: pirofillit).

Figure 9. Photomicrpgraphs of common alteration type in the study area: a) thin section view of proplytic alteration (SIS-1130, 5X,CN), b) argillic alteration from andesitic lavas (SIS-1125, 5X, CN), c) alunite crystals in cavities (SIS-1014, 10X, CN), d) alunite crystals and diaspore mineral in propylitic groundmass, (SIS$48 / 90928,10 X, C N), \boldsymbol{e})$ vuggy silica, (SISY-23, 10X, CN), f) early stage silicification (fine grain), late stage silicification (coarse grain) (SISY-67, 5X, CN). CN: crossed nicols, Arg.Alt: argillic alteration, plj: plagioclase, ep: epidote, cal: calcite, chl: chlorite, ep: epidote, alu: alunite, qzt: guartz, dsp: diaspore, prl: pyrophyllite). 
Sfalerit minerali gri renklidir. Yansıması düşüktür, manyetitin yansımasıyla yaklaşıkaynıdır. İzotroptur. Bileşimine ve $\mathrm{Fe}$ konsantrasyonuna göre, kahverengi, kırmızımsı renkte iç yansıma gösterir. Özellikle yüksek sıcaklıkta oluşan yataklarda, sıklıkla küçük kalkopirit, pirotin veya stannit eksolüsyon topları (bleb) içerir (Picot ve Johan, 1982) Ayrica kalkopirit içerisinde 4 sivrilmiş köşeli yıldızlı (four-pointed stars) dantel gibi taneler şeklinde kapanım olarak da oluşabilir. İncelemelerde çoğunlukla özşekilsiz kapanımlar halinde veya yarı özşekilli kristalli olarak pirit ile birlikte gözlenmiştir. Kristal olarak gözlendiği örneklerde az miktarda çok küçük kalkopirit kapanımları içermektedir.

Hematit; beyaz, gri-beyaz renktedir. Özellikle piritin kontağında belirgin mavimsi tonlardadır. Pleokroyizması oldukça zayıftır. Yansıması ortadir, tetrahedrit-tennantit minerallerinin yansımasıyla yaklaşık aynı, manyetit, ilmenit ve rutilden daha yüksektir. Yeşilimsi griden açık kahverengimsi renk tonlarına değişen belirgin bir anizotropisi vardır. Kırmızı iç yansıması oldukça yaygın olarak gözlenmektedir.

Manyetit; kahverengimsi gri renktedir. Yansıması düşüktür, sfaleritin yansımasıyla yaklaşık aynı ve hematitin yansımasından çok daha düşüktür. İzotroptur. Bazı kesitlerde piritler içerisinde kapanım olarak gözlenmiştir. Ancak çoğunlukla hematit ile birlikte gözlenmiştir.

Yüzeysel bozunma süreçleriyle
manyetit mineralinin hematit mineraline
dönüşmesiyle oluşan martitleşme yaygın olarak
gözlenmiştir. Ornatma tane kenarından içe doğru
gerçekleşmektedir (Şekil 10f).

Götit minerali, gri-beyaz renktedir ve sıklıkla birlikte bulunduğu minerallerle karşılaştırıldığında mavimsi tonlardadır. Yansıması oldukça düşük ve oldukça değişkendir. Yansıması, bünyesindeki su içeriği arttıkça (limonit) daha da düşer. Sfalerit ve manyetitin yansımasıyla yaklaşık aynıdır (manyetitin yansımasından biraz daha düşük), hematitin yansımasından oldukça düşüktür. Mavimsi tonlarda anizotropi gösterir, ancak kırmızı, turuncu veya sarımsı renklerdeki iç yansıması nedeniyle anizotropisi kısmen maskelenebilir. Bazı kolloform türleri tamamen izotropiktir (stilpnosiderit ve limonit). Kolloform dokusu tipiktir. Bazı kesitlerde zonlu kristaller şeklinde gelişmiştir.

Hematit, manyetit, götit mineralleri oksidasyon zonunu temsil etmektedirler.

Kovelin, kalkosin mineralleri süperjen cevherleşmelerdir. Kalkopirit ve bornit minerallerinden itibaren dönüşmüşlerdir.

\section{IZOTOP JEOKIMYYASI}

Bu çalışma kapsamında pirit, kalkopirit, K-alünit ve barit minerallerinde kükürt duraylı izotop analizi $\left(\delta^{34} \mathrm{~S}\right)$, kuvars ve K-alünit minerallerinde oksijen ve döteryum duraylı izotop analizi $\left(\delta^{18} \mathrm{O}\right.$, $\delta \mathrm{D})$ ve K-alünit ve hornblend minerallerinde ${ }^{40} \mathrm{Ar} /{ }^{39} \mathrm{Ar}$ radyojenik izotop analizi yapılmıştır.

K-alünit ve Na-alünit minerallerinde $\delta^{18} \mathrm{O}$ ve $\delta \mathrm{D}$ analizi, Yeni Zelenda'da GNS Science Laboratuvarı'nda, yaptırılmıştır.

Kuvarslarda oksijen izotop analizi ve içerisindeki sıvı kapanımlardan itibaren döteryum analizi US. Geological Survey'in Denver Sıv1 Kapanım Analiz Laboratuvarında (DIAL) yapılmıştır.

Kuvars içerisindeki sıvı kapanımlardaki hidrojen izotop bileşimi Delta kütle spektrometresi ile eşleşmiş otomatik termokimyasal konversiyon element analiz cihazı kullanılarak analiz edilmiştir.

Pirit, kalkopirit, barit ve K-alünit minerallerinde $\delta^{34} \mathrm{~S}$ izotop analizi Nevada Reno 
Üniversitesi Duraylı İzotop Laboratuvarı'nda yapılmıştır.

$\mathrm{Cu}$ izotop analizleri için örnek hazırlama Juniata Kolej, Huntingdon-PA'da, Cu-içeren birincil minerallerden (kalkopirit, bornit) itibaren $\mathrm{Cu}$ izotop analizleri Arizona Eyalet ve Pensilvanya Eyalet Üniversitelerinde gerçekleştirilmiştir.

$\delta^{18} \mathrm{O}$ değerleri $\%$ o +12.0 ve $\%$ o- 11.3 olarak belirtilen uluslararas1 IAEA-SO-5 ve IAEA-SO-6 standartlarına göre normalize edilen VSMOW'a göre raporlanmıştır. Standartların doğruluğu \%o $0,5^{\prime}$ dir.

$\delta \mathrm{D}$ değerleri $\%$ - $100, \% 066$ ve $\%$ 118 olarak belirtilen uluslararas1 IAEA-CH-7 ve NBS30 ve NBS22 standartlarına göre normalize edilen VSMOW'a göre raporlanmıştır. Standartların doğruluğu \%o1,5'dir.

S izotop analizleri Giesemann ve diğ., 1994'te belirtilene benzer yöntemle yürütülmüştür. Analizler GSL (Green Sphalerite), UGLI (Galena), BSL (Brown Sphalerite) ve MIC (Chalcopyrite) standartları kullanılarak kalibre edilmiştir. Hata oranı \pm \%o 0,2 dir. Değerler V-CDT'e ( Vienna Canyon Diablo Troilite) göre rapor edilmiştir.

K-alünit ve hornblend minerallerinde ${ }^{40} \mathrm{Ar} /{ }^{39} \mathrm{Ar}$ yaş analizi, Nevada Las Vegas Üniversitesi’nde yaptırılmıştır. Örneklerde 1şın yayma işlemi, Denver, Colorado' da U. S. Geological Survey TRIGA Reaktöründe, $1 \mathrm{MW}$ TRIGA tip reaktörde 1şın yayma tüp merkezinde (In-Core Irradiation Tube, ICIT) 7 saat boyunca 1şımaya bırakılarak gerçekleştirilmiştir.

\section{Oksijen ve Döteryum İzotop Analizi}

$\mathrm{Bu}$ çalışmada, silisleşmenin derecesini ve cevherleşme ile alterasyonu oluşturan sıvının kaynağını tespit etmek amacıyla oksijen ve döteryum analizi dört adet kuvars ve iki adet
K-alünit mineralinde yapılmıştır. Kuvars ve $\mathrm{K}$-alünitlerden elde edilen $\delta^{18} \mathrm{O}$ ve $\delta \mathrm{D}$ değerleri Çizelge 1'de topluca verilmiştir. Kuvarslar silisli zonlardan alınmıştır. Seçilen numunelerde belirlenen mineraller mikroskop altında elle ayrılmıştır.

Kuvarslarda elde edilen $\delta^{18} \mathrm{O}$ değeri \%o 7,1 ile \%o 15,6 arasında değişirken ortalama değeri \%o 11,5 dir. K-alünitlerde elde edilen $\delta^{18} \mathrm{O}$ değeri \% 10,1 ve \%o 11,4 dir. Na-alünitlerden elde edilen $\delta^{18} \mathrm{O}$ değerleri \%o 8,5 ve \%o 12,4 tür.

Kuvarslarda bir örnek hariç (EVT28/6) $\delta \mathrm{D}$ ölçüm yapılamamıştır. Ölçülen değerler dedeksiyon limitinin altında olduğu için belirlenememiştir. Kuvarslarda ölçülebilen tek $\delta \mathrm{D}$ değeri \%o -77 dir. K-alünitlerden elde edilen $\delta \mathrm{D}$ değerleri \%o -55,2 ve \%o $-57,6$ dır. Na-alünitlerden elde edilen $\delta \mathrm{D}$ değerleri \%o $-25,3$ ve \%o -61'dir.

Oksijen ve döteryum izotop verilerine göre, Sisorta yüksek sülfidasyon epitermal altın yatağının oluşumunda etkin olan çözeltinin meteorik hidrotermal kökenli sulardan itibaren kısmende magmatik suyun katılımı ile geliştiği söylenebilir. Orta Anadoluya ait güncel suların $\delta^{18} \mathrm{O}$ ve $\delta \mathrm{D}$ değerlerinin meteroik su çizgisine plot edildiği gözlenmektedir (Şekil 11).

\section{Kükürt İzotop Analizi}

$\mathrm{Bu}$ çalışmada cevherleşme ve alterasyonda etkili olan kükürtün kaynağını tespit etmek amacıyla; 14 adet pirit, 3 adet kalkopirit, 2 adet K-alünit ve 5 adet barit mineralinde kükürt izotop analizi yapılmıştır. $\delta^{34} \mathrm{~S}$ analiz sonuçları topluca Çizelge 2 'de verilmiştir. Numuneler yüzeyden ve sondaj karotlarından seçilmiştir. Seçilen numunelerde belirlenen mineraller mikroskop altında elle ayrılmıştır. 

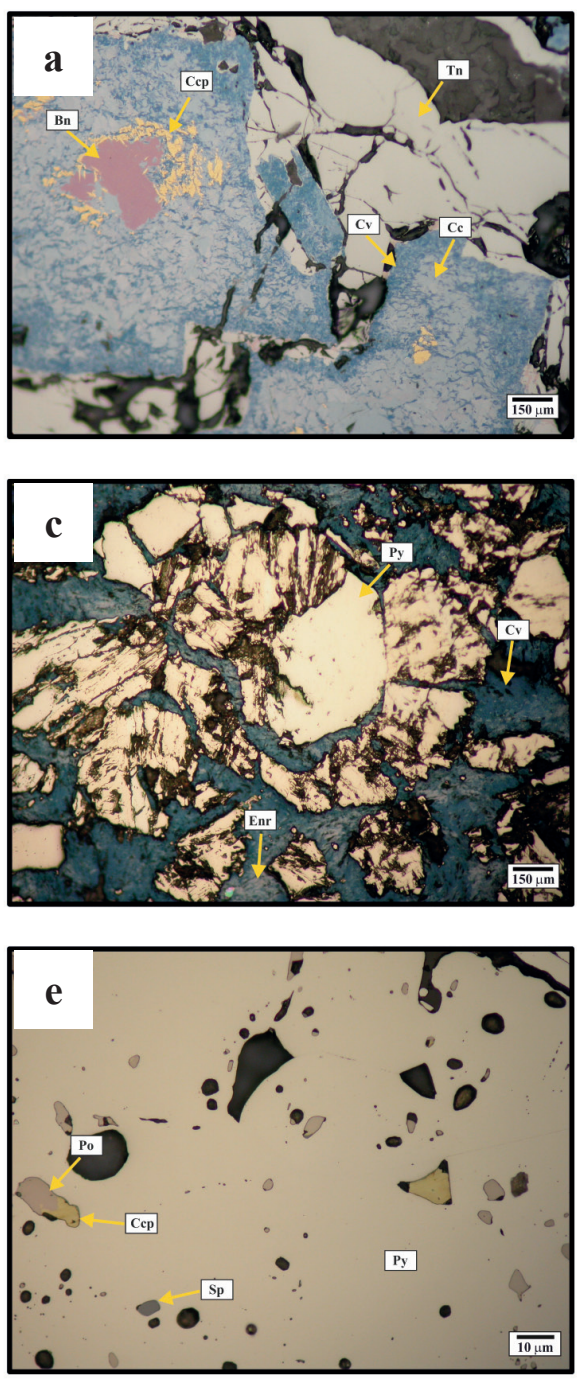
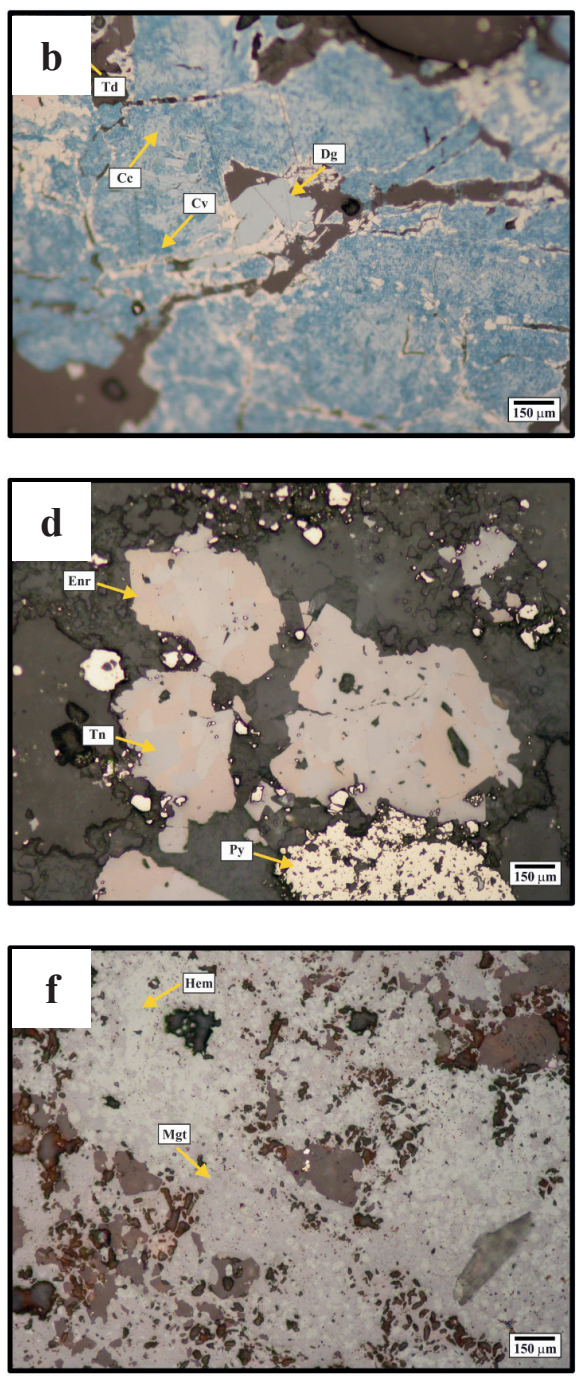

Şekil 10. Çalışma alanında gözlenen yaygın cevher minerallerin mikrofotoğrafları: a) Kalkosin, kovelin ve bornitin kalkopiritten itibaren gelişimi (SIS-30/86597, 20X, TN), b) Birincil ve yüksek sicaklık minerali dijenit ve ondan sonra gelişen ikincil mineraller (SIS-30/86597, 20X, TN) c) Piritten sonra ikincil olarak enarjit, kalkosin ve kovelinin gelişimi (SIS-50/87410, 20X, TN) d) Enarjit, tennnantit minerallerince ornatılan pirit kalıntıları (SIS-21/86224, 20X, TN) e) Pirit içerisinde kalkopirit, sfalerit ve pirotin kapanımları (SIS-47/73239, 50X, TN) f) Damlacıklar şeklinde martitleşme (manyetit mineralinin hematit mineraline dönüşmesi) (SIS-38/88946, 20X, TN). TN: tek nikol, Bn: Bornit, Cc: kalkosin, Ccp: kalkopirit, Cv: kovelin, Dg: dijenit, Td:tedraedrit, Enr: enarjit, Py: pirit, Tn: tennantit, Hem: hematit, Mgt: manyetit, Sp: sfalerit, Po: pirotin,).

Figure 10. Photomicrographs of common ore minerals from the study area: a) chalcocite, covelline and bornite development after chalcopyrite (SIS-30/86597, 20X, UN), b) secondary mineral occurrences after primary high temperature digenite mineral (SIS-30/86597, 20X, UN), c) pyrite relicts after replacement by enargite and tennatite (SIS-21/86224, 20X, UN), d) chalcopyrite, sphalerite, pyrotine minerals as inclusions in pyrite (SIS-47/73239, 50X, UN), e) secondary enargite, chalcosine and covelline occurences after pyrite (SIS-50/87410, 20X, UN), f) martizitation as droples (hematite occurences after magnetite) (SIS-38/88946, 20X, UN). UN: uncrossed nicol, fBn: Bornite, Cc: kalkosin, Ccp: chalcoyrite, Cv: covellite, Dg: digenite, Td:tedrahedrite, Enr: enagite, Py: pyrite, Tn: tennantite, Hem: hematite, Mgt: magnetite, Sp: sphalerite, Po: pyrrhotite. 
Çizelge 1. Minerallerin $\delta^{18} \mathrm{O}$ ve $\delta \mathrm{D} \%$ analiz değerleri.

Table 1. $\delta^{18} \mathrm{O}$ ve $\delta D \%$ analytical data of minerals.

\begin{tabular}{|l|l|l|l|}
\hline Örnek No & $\boldsymbol{\delta}^{\mathbf{1}} \mathbf{O}$ & $\delta \mathrm{D}$ & Mineral \\
\hline SIS-1199 & 7,1 & - & Kuvars \\
\hline SIS-1216 & 10,4 & - & Kuvars \\
\hline SIS-1245 & 15,6 & - & Kuvars \\
\hline EVT-28/6 & 12,8 & -77 & Kuvars \\
\hline EVT-20/1 & 11,4 & $-55,2$ & K-Alünit \\
\hline SIS-2/70438 & 10,1 & $-57,6$ & K-Alünit \\
\hline SIS-1235 & 8,5 & $-25,3$ & Na-Alünit \\
\hline SIS-3/70472 & 12,4 & $-61,0$ & Na-Alünit \\
\hline
\end{tabular}

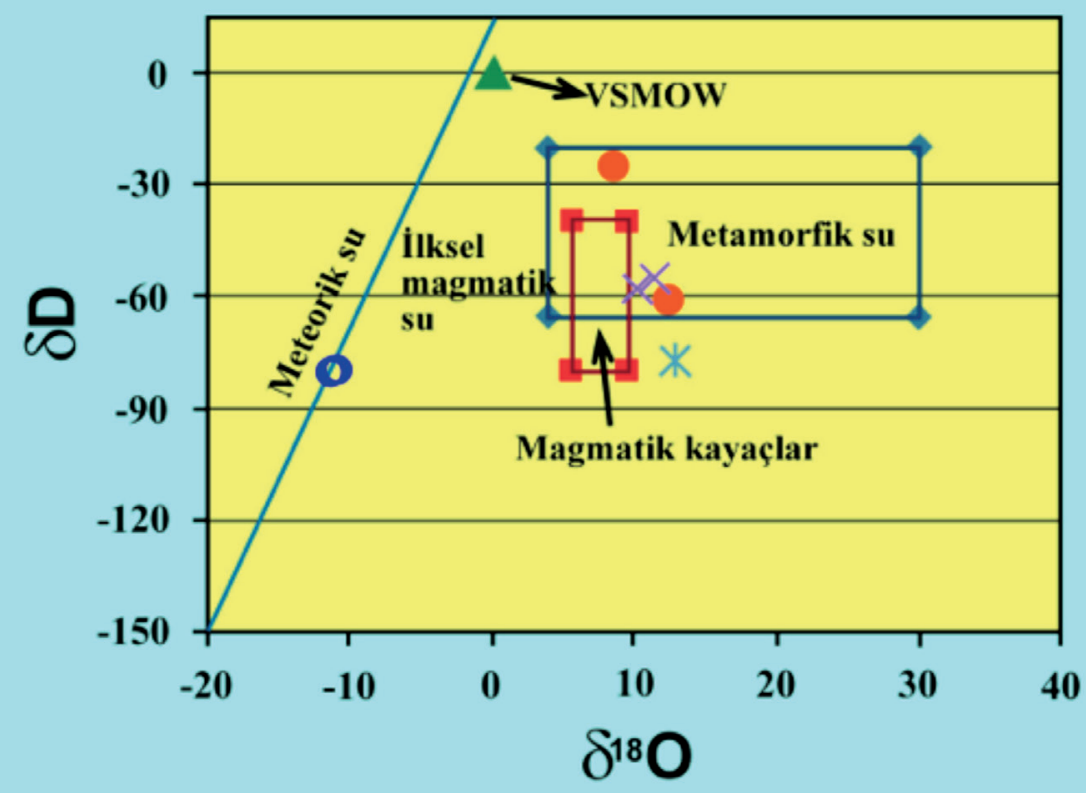

Metamorfik

Magmatik

VSMOW

Kuvars

K-Alünit

Na-Alünit

OOrta Anadolu

meteorik su

alanı

Şekil 11. Çalışma alanındaki kuvars ve alunit örneklerine ait oksijen ve hidrojen izotop değerlerinin, yaygın jeolojik ortamlarla birlikte $\delta^{18} \mathrm{O}-\delta \mathrm{D}$ diyagramında gösterimi. Metamorfik ve iksel magmatik su alanları Taylor, (1997)'den, meteorik su çizgisi Craig, (1961)'den, Orta Anadolu meteorik su alanı Uçurum ve diğ. (2007)'den alınmıştır.

Figure 11. $\delta^{18} O-\delta D$ diagram of quartz and alunite samples from study area with common geological environments. Metamorphic water and primitive magmatic water areas are from Taylor, (1997), meteoric water is from Craig (1961), Central Anatolia water area is from Ucurum et al, (2007). 
Çizelge 2. Çalışma alanındaki örneklerin $\delta^{34} \mathrm{~S} \%$ analiz değerleri.

Table 2. $\quad \delta^{34} S \%$ data of samples from study area.

\begin{tabular}{|l|l|l|l|}
\hline Örnek No & $\mathbf{\delta}^{34} \mathbf{S}$ & Mineral & Derinlik (yüzeyden itibaren) \\
\hline EVT-9/1 & $-9,4$ & Pirit & $349.90 \mathrm{~m}$ \\
\hline EVT-18/1 & $-6,2$ & Pirit & $22.50 \mathrm{~m}$ \\
\hline EVT-26/1 & $-9,6$ & Pirit & $60.75 \mathrm{~m}$ \\
\hline EVT-26/5 & $-10,0$ & Pirit & $58.30 \mathrm{~m}$ \\
\hline EVT-28/1 & $-1,7$ & Pirit & $616.20 \mathrm{~m}$ \\
\hline EVT-35/3 & $-7,9$ & Pirit & $39.50 \mathrm{~m}$ \\
\hline Int-1 & $-4,0$ & Pirit & yüzey \\
\hline Int-2 & $-5,8$ & Pirit & yüzey \\
\hline SIS-1133 & $-1,7$ & Pirit & yüzey \\
\hline SIS-1134 & $-0,4$ & Pirit & yüzey \\
\hline SIS-38/89005 & $-6,4$ & Pirit & $133-134 \mathrm{~m}$ \\
\hline SIS-38/89029 & $-6,3$ & Pirit & $162-163 \mathrm{~m}$ \\
\hline SIS-52/91086 & $-8,1$ & Pirit & $74.70-75.50 \mathrm{~m}$ \\
\hline SIS-59/92289 & $-1,6$ & Pirit & $113.90-115.30$ \\
\hline Int-3 & 2,3 & Kalkopirit & yüzey \\
\hline SIS-47/73239 & 1,5 & Kalkopirit & $134.5-136 \mathrm{~m}$ \\
\hline SIS-47/73252 & 1,8 & Kalkopirit & $149.30-150.40 \mathrm{~m}$ \\
\hline SIS-2/70438 & 21,8 & K-Alünit & $63.20-64.80 \mathrm{~m}$ \\
\hline EVT-20/1 & 22,0 & K-Alünit & $15.90 \mathrm{~m}$ \\
\hline SISY-45 & 17,4 & Barit & yüzey \\
\hline SISY-50 & 16,5 & Barit & yüzey \\
\hline SISY-60 & 16,2 & Barit & yüzey \\
\hline SISY-63 & Barit & yüzey \\
\hline EVT-32/3 & Barit & $29.90 \mathrm{~m}$ \\
\hline & 17,3 & & \\
\hline
\end{tabular}

Piritlerde $\delta^{34} \mathrm{~S}$ değerleri \%o $-0,4$ ile $\%$ $-10,0$ arasinda, kalkopiritlerde \%o 1,5 ile \%o 2,3 arasinda, K-alünitlerde \%o 21,8 ile \%o 22,0 arasinda ve baritlerde \%o 16,2 ile \%o 18,6 arasinda değişmektedir.

0 \%o' a yakın ve çok dar bir aralıkta olan $\delta^{34} \mathrm{~S}$ değerlerinin magmatik kayaçlara ait olduğu, sedimanter kayaçlara ait $\delta^{34} \mathrm{~S}$ değerlerinin çok geniş bir aralıkta dağılım gösterdiği, -\%o $20+\%$ o 20 arasında değişen $\delta^{34} \mathrm{~S}$ değerlerinin metamorfik kayaçlara ait olduğu ve okyanus suyuna ait $\delta^{34} \mathrm{~S}$ değerinin $20 \%$ olduğu bilinmektedir (Şekil 12).
$0 \%$ 'a çok yakın $\delta^{34} \mathrm{~S}$ değerleri magmatik kökenli kükürtü, \%o -10 'dan daha hafif $\delta^{34} \mathrm{~S}$ değerleri bakteriyel süreçlerle indirgenmiş kükürtü, $\%+10$ 'dan daha büyük $\delta^{34} \mathrm{~S}$ değerleri deniz suyundan inorganik ( \pm organik) olarak indirgenmiş kükürtü göstermektedir.

Piritlerde yapılan analiz sonucu $\delta^{34} \mathrm{~S}$ değerleri \%o -0,4 ile \%o -10 arasında olduğu ve magmatik kükürtün sülfatlı ve sülfürlü mineraller arasında paylaşımı sonucu sülfürlü minerallerde hafif kükürtün kullanıldığı veya magmatik kükürt içeren kaynaklardan hidrotermal çözeltilerce hafif kükürtün tercihli olarak çözüldüğü şeklinde yorumlanabilir. 
Kalkopiritlerde, $\quad \delta^{34} \mathrm{~S} \quad \% \quad \quad 1,5-2,3$ arasındaki değerler hidrotermal çözeltinin ve çevrenin fizikokimyasal koşullarına bağlı olarak magmatik kükürtün ağır kısmının ayrımlanarak kullanımı şeklinde yorumlanabilir (Şekil 12). Barit ve K-alünit örneklerinde ağır $\delta^{34} \mathrm{~S}$ izotopca zenginleşme (Çizelge 2), bunların hidrotermal evrenin son ürünleri olarak çözelti ve/veya alterasyon süreci sonucu oluştuklarını göstermesi bakımından önemlidir.

\section{Cu İzotop Analizi}

Bakır izotop analizi 5 sondaj örneğinde yapılmış, ancak bunlardan yüzeydeki intrüzyondan elde edilen kalkopirit örneğinde herhangi bir sinyal detekte edilmemiştir (Çizelge 3). Bu büyük olas1lıkla kalkopiritin denge durumunda olmas1 nedeniyle hiç bir $\mathrm{Cu}$ izotopu sinyali vermemiştir. Bakır izotop analiz sonuçları
${ }^{65} \mathbf{C u}=\left[\frac{\left(\frac{{ }^{65} \mathrm{Cu}}{{ }^{63} \mathrm{Cu}}\right)_{\text {örnek }}}{\left(\frac{{ }^{65} \mathrm{Cu}}{{ }^{63} \mathrm{Cu}}\right)_{\text {standart }}}-1\right] \times \mathbf{1 0}^{3}$ denklemi ile rapor

Bakır izotop analiz sonuçlarına bakıldığında yüzeye yakın (oksidasyon zonunda) örnekte (SİS-50 87410) hafif izotopça zenginleşme $\left(\delta^{65} \mathrm{Cu} \%=-5,502\right)$ derinlerde ise (SİS-30 86597) ağır izotoplarca $\left(\delta^{65} \mathrm{Cu} \%=3,032\right)$ zenginleşme görülmektedir. $\mathrm{Bu}$ da Sisorta yüksek sülfidasyon epitermal altın yatağının altında olası bir porfiri sistemin YAS seviyesinin altındaki Cu'ca zenginleşme zonuna yakınlığını işaret edebilir. Buna ek olarak, SíS-47 $73252\left(\delta^{65} \mathrm{Cu} \%=0,458\right)$ ve SİS-30 $8620\left(\delta^{65} \mathrm{Cu} \%=-0,997\right)$ hipojen zonu işaret etmesi bakımından önem taşımaktadır.

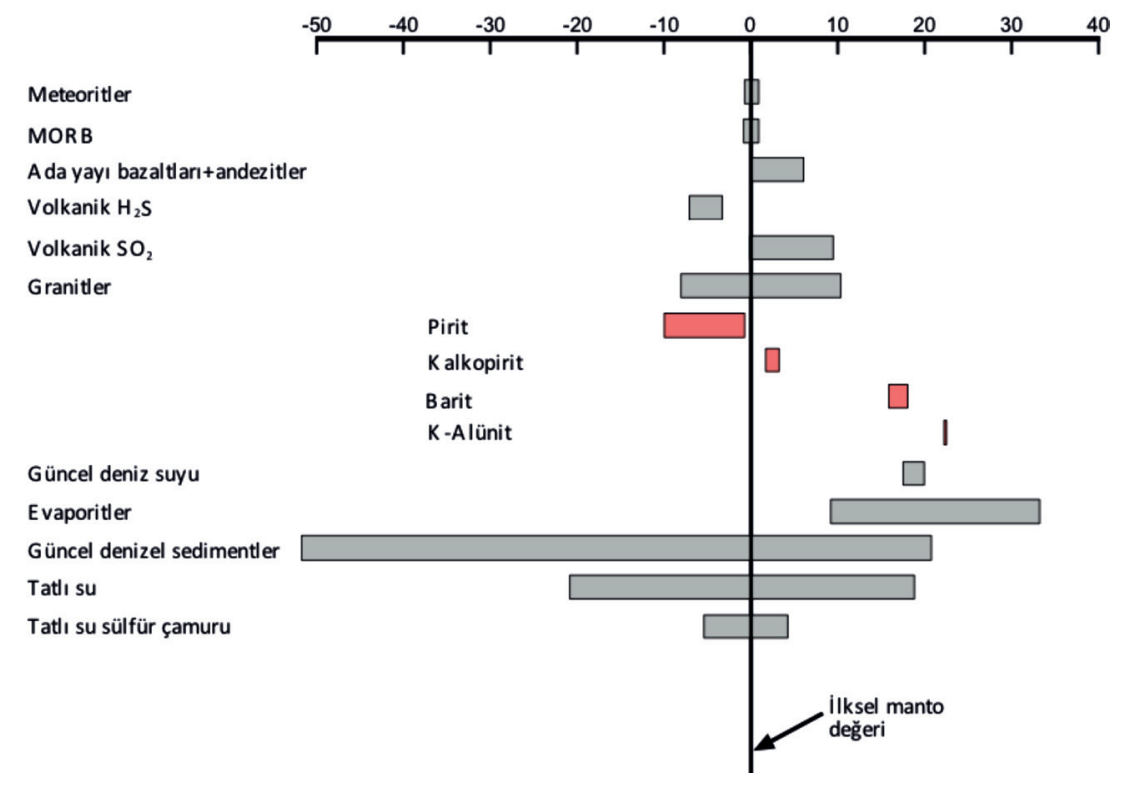

Şekil 12. Pirit, kalkopirit, barit ve K-alünit minerallerine ait $\delta^{34} \mathrm{~S}$ değerlerinin, yaygın kayaç grupları ve su kaynaklarının $\delta^{34} \mathrm{~S}$ dağılımları ile karşılaştırılması. Veriler, Sakai ve diğ., 1982, 1984; Ueda ve Sakai, 1984; Claypool ve diğ.,1980; Kerridge ve diğ., 1983; Chambers, 1982; Coleman, 1977; Chaussidon ve diğ.,1989'dan alınmıştır.

Figure 12. $\delta^{34} S$ data of pyrite, chalcopyrite, barite and K-alunite samples from study area, and comparison with common rock groups and water resources. Data are from Sakai et al, (1982, 1984); Ueda and Sakai, (1984); Claypool et al, (1980); Kerridge et al, (1983); Chambers, (1982); Coleman, (1977); Chaussidon et al, (1989). 
Çizelge 3. Sisorta Au yatağına ait sondaj karot örneklerinden $\mathrm{Cu}$-içeren minerallerin $\delta^{65} \mathrm{Cu}$ izotop analizleri.

Table 3. $\quad \delta^{65} \mathrm{Cu}$ isotope analytical results of Cu-bearing minerals from drill core samples of Sisorta Au deposit.

\begin{tabular}{|l|l|l|l|}
\hline Örnek No & $\boldsymbol{\delta}^{\mathbf{6 5}} \mathbf{C u}$ \%o & $\begin{array}{l}\text { Derinlik (yüzeyden } \\
\text { itibaren }\end{array}$ & Mineral \\
\hline Sis-47 73252 & 0.458 & $149.30-150.40 \mathrm{~m}$ & Kalkopirit \\
\hline Sis-30 86597 & 3.032 & $114-115.30$ & Bornit+kalkopirit \pm kovelin,kalkosin \\
\hline Sis-30 86620 & 0.997 & $144-145.10$ & Pirit, kalkopirit, bornit \\
\hline Sis-50 87410 & -5.502 & $53.45-54.30$ & Enarjit, pirit, kovelin, kalkosin \\
\hline Cpy-İntrüzyon & $\begin{array}{l}\text { Dengede olduğu için } \\
\text { sinyal alınamad1 }\end{array}$ & yüzey & Kalkopirit \\
\hline
\end{tabular}

Sisorta yüksek sülfidasyon epitermal altın yatağına eşlik eden bakır minerallerinde elde edilen $\delta^{65} \mathrm{Cu} \%$ izotop değerleri (Çizelge 3) yüksek sülfidasyon epitermal altın yatağının altında/yakıında gömülü bir porfiri $\mathrm{Cu}$ sistemini işaret edebilir.

Tipik bir porfiri $\mathrm{Cu}, \mathrm{Cu}-\mathrm{Au}$, yatağında yıkanma (oksit) zonunda $\delta^{65} \mathrm{Cu} \%$ o'in tüketildiği yani hafif izotoplarca zenginleştiği (Şekil 13), YAS altında zenginleşme zonunda $\delta{ }^{65} \mathrm{Cu} \%$ 'in maksimum düzeye eriştiği, yani ağır izotoplarca zenginleştiği, ilksel (primer) zonda ise $\delta{ }^{65} \mathrm{Cu}$ \%o'in 0'a yakın değerler aldı̆̆ı değişik araştırıcılar (Larson ve diğ., 2003; Graham ve diğ., 2004; Mathur ve diğ., 2009a,b; Li ve diğ., 2010; Mathur ve diğ., 2010; Mirnejad ve diğ., 2010; Braxton ve Mathur, 2011; Garofali ve diğ., 2012; Ikehata ve Hirata, 2012) tarafından belirtilmiştir. Farklı jeolojik ortamlara ilişkin Cu izotop analiz değerleri Şekil 14'de özetlenmiştir.

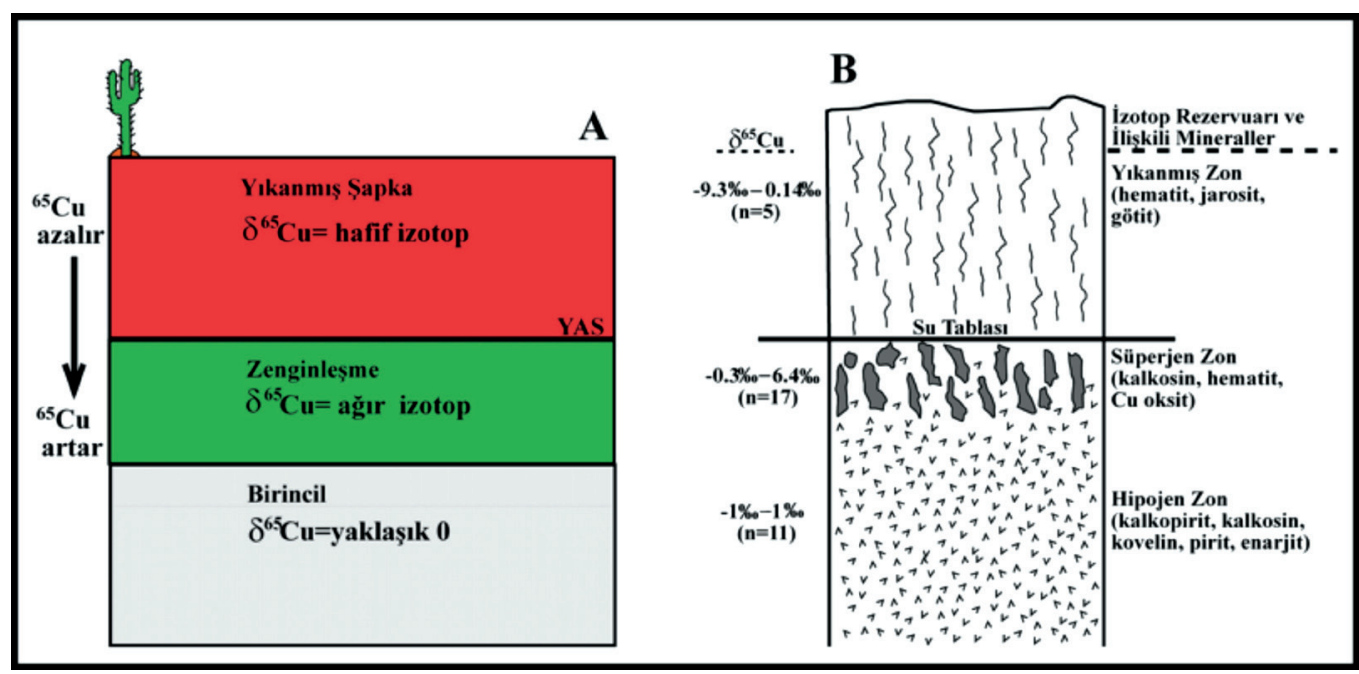

Şekil 13. Tipik bir porfiri $\mathrm{Cu}$ sisteminde $\delta^{65} \mathrm{Cu} \%$ 'in dağılım1, A) Mathur ve diğ., 2009b'den, B) Mirnejad ve diğ., 2010'dan alınmıştır.

Figure 13. Variation of $\delta^{65} \mathrm{Cu} \%$ in typical porphyry Cu deposit, A) is from Mathur et al 2009b, B) is from Mirnejad et al, 2010. 


\section{Ar-Ar Yaş Analizi}

Çalışma alanında alterasyonun ve cevherleşmenin yaşını belirleyebilmek amacıyla bir adet hornblend ve iki adet K-alünit mineralinde Ar-Ar yaşlandırma analizi yapılmıştır.Yapılan analizlerin sonucunda

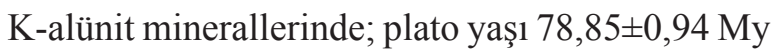
ve $76,59 \pm 2,19 \mathrm{My}$, izokron yaş $78,25 \pm 0,42 \mathrm{My}$ ve $75,30 \pm 0,90$ My olarak, hornblend mineralinde ise plato yaşı $80,44 \pm 0,84 \mathrm{My}$ elde edilmiştir.

SIS-2/70438 numaral1 K-alünit mineraline ait analiz sonuçları adım adım Çizelge 4'de verilmiştir. Bu örnekte, 2. adımdan itibaren genellikle dereceli olarak artarak yaklaşı 72,5
My yaşl1, hemen hemen düz bir yaş spektrumu

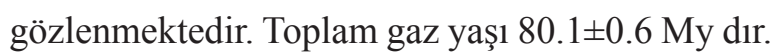
Dördüncü ve altıncı adımlar arasında ( ${ }^{39} \mathrm{Ar}$ 'un \%

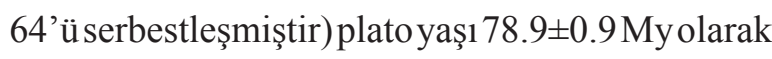
tanımlanmaktadır (Şekil 15). Dördüncü ve yedinci adımlar arasında ( ${ }^{39} \mathrm{Ar}$ 'un \% 65'i serbestleşmiştir) ilksel ${ }^{40} \mathrm{Ar} /{ }^{36} \mathrm{Ar}$ oranının $309.7 \pm 1.9$ olduğu artık argonun bulunduğu ve $78.3 \pm 0.4$ My yaş veren izokron tanımlanmaktadır (Şekil 16). Son üç adım hariç ( $\% 1$ 'den daha az ${ }^{39} \mathrm{Ar}$ serbestleşmiştir) $\mathrm{Ca} / \mathrm{K}$ oranları homojen alünit mineralinin gaz çıkışı (outgassing) ile uyumludur. Radyojenik ürünler $\left(\%{ }^{40} \mathrm{Ar}^{*}\right)$ bu mineral için anlamlıdır ve sonraki bir alterasyonu göstermemektedir.

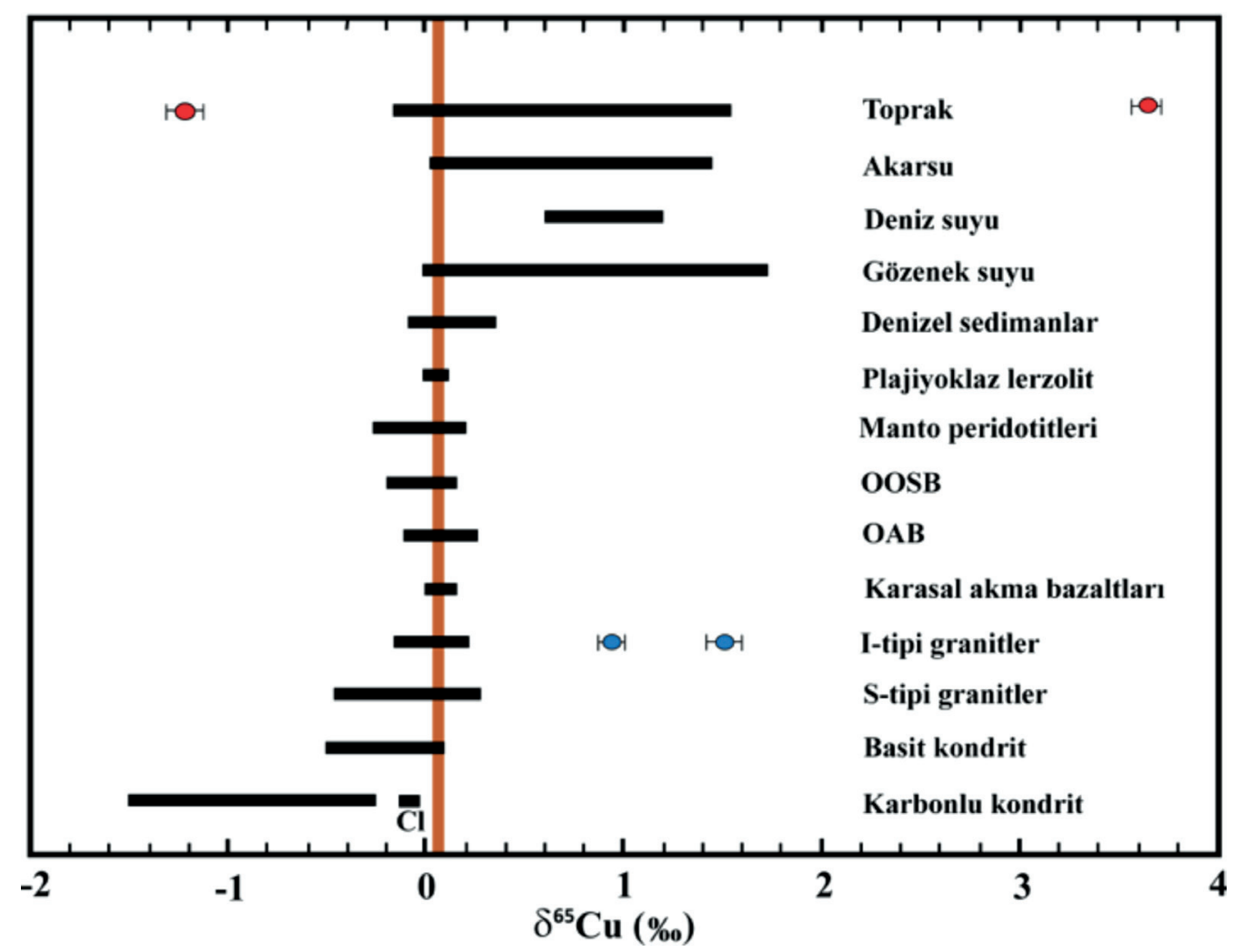

Şekil 14. Farklı jeolojik rezervuar ve kayaçlara ait $\delta^{65} \mathrm{Cu} \%$ izotop değişim oranları (Liu ve diğ, 2015'den alınmıştır).

Figure 14: $\delta^{65} \mathrm{Cu} \%$ variations from different geological reservoirs (adapted from Liu et al, 2015). 
Çizelge 4. SIS-2/70438 numaralı K-alünit mineralinde yapılan Ar-Ar yaşlandırma analizi verileri.

Table 4. Ar-Ar analytical age data of K-alunite mineral, SIS-2/70438.

\begin{tabular}{|c|c|c|c|c|c|c|c|c|c|c|c|c|c|}
\hline step & T (C) & $t$ (min.) & ${ }^{36} \mathrm{Ar}$ & ${ }^{37} \mathbf{A r}$ & ${ }^{38} \mathrm{Ar}$ & ${ }^{39} \mathrm{Ar}$ & ${ }^{40} \mathrm{Ar}$ & $\%^{40} \mathrm{Ar} *$ & $\begin{array}{l}\% \\
{ }^{39} \mathrm{Ar} \\
\text { rlsd }\end{array}$ & $\mathrm{Ca} / \mathrm{K}$ & $\begin{array}{l}{ }^{40} \mathrm{Ar} * / \\
{ }^{39} \mathrm{ArK}\end{array}$ & $\begin{array}{l}\text { Age } \\
\text { (Ma) }\end{array}$ & 1s.d. \\
\hline 1 & 700 & 12 & 4,135 & 0,009 & 0,862 & 5,732 & 1297,43 & 11,2 & 4,6 & 0,0588 & 25,592 & 75,86 & 3,71 \\
\hline 2 & 730 & 12 & 0,700 & 0,006 & 0,324 & 13,525 & 520,687 & 63,4 & 10,8 & 0,0166 & 24,451 & 72,54 & 0,85 \\
\hline 3 & 740 & 12 & 0,461 & 0,010 & 0,419 & 24,165 & 736,244 & 83,3 & 19,3 & 0,0155 & 25,512 & 75,63 & 0,78 \\
\hline 4 & 750 & 12 & 0,467 & 0,010 & 0,568 & 35,383 & 1053,92 & 88,1 & 28,3 & 0,0106 & 26,451 & 78,35 & 0,79 \\
\hline 5 & 760 & 12 & 0,656 & 0,020 & 0,564 & 33,594 & 1065,00 & 83,3 & 26,8 & 0,0223 & 26,622 & 78,84 & 0,81 \\
\hline 6 & 770 & 12 & 0,641 & 0,010 & 0,265 & 10,563 & 460,712 & 62,2 & 8,4 & 0,0355 & 27,141 & 80,35 & 1,13 \\
\hline 7 & 790 & 12 & 0,594 & 0,009 & 0,135 & 1,401 & 207,271 & 21,2 & 1,1 & 0,2408 & 30,950 & 91,34 & 2,50 \\
\hline 8 & 840 & 12 & 2,665 & 0,090 & 0,578 & 0,487 & 882,006 & 15,9 & 0,4 & 6,9413 & 293,778 & 723,00 & 29,60 \\
\hline 9 & 910 & 12 & 0,471 & 0,009 & 0,092 & 0,173 & 136,555 & 4,8 & 0,1 & 1,9510 & 37,857 & 111,11 & 13,44 \\
\hline 10 & 1000 & 12 & 0,229 & 0,005 & 0,050 & 0,164 & 68,216 & 9,0 & 0,1 & 1,1431 & 33,355 & 98,25 & 9,68 \\
\hline \multicolumn{9}{|c|}{ Serbest kalan toplam ${ }^{39} \mathrm{Ar}$} & 100 & \multicolumn{2}{|c|}{ Toplam gaz yaşı } & 80,11 & 0,57 \\
\hline & & & & & & & & & & \multicolumn{2}{|c|}{ Plato yaşı } & 78,85 & 0,94 \\
\hline & & & & & & & & & & \multicolumn{2}{|c|}{ İzokron yaş1 } & 78,25 & 0,42 \\
\hline
\end{tabular}

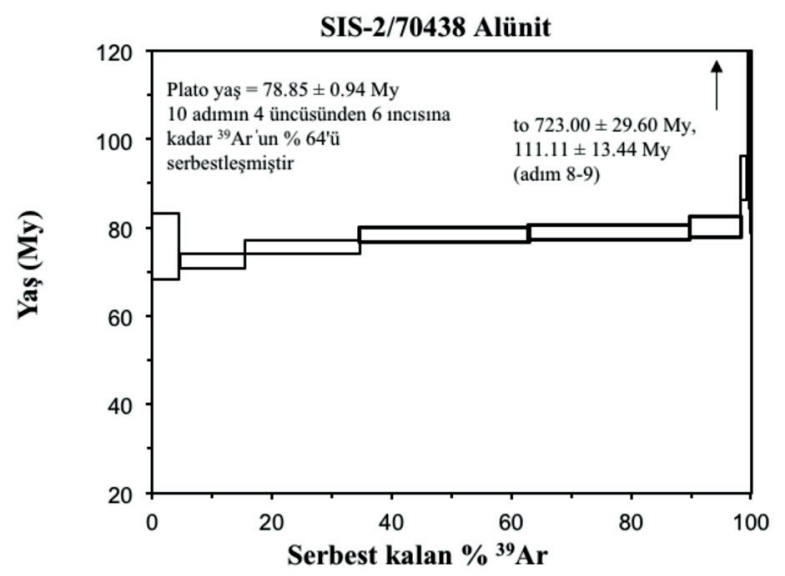

Şekil 15. SIS-2/70438 numaralı K-alünit mineraline ait plato yaşını gösteren spektrum.

Figure 15. Plateau age spectrum of K-alunite sample, SIS-2/70438.

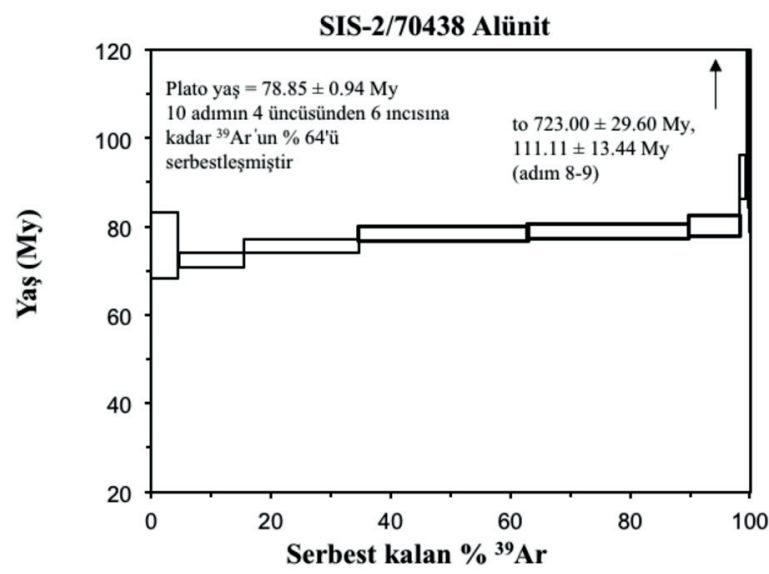

Şekil 16. SIS-2/70438 numaralı K-alünit mineralinin izokron yaşını gösteren grafik.

Figure 16. Isochron age graph of K-alunite sample, SIS-2/70438. 
EVT-20/1 numaralı K-alünit mineraline ait analiz sonuçları adım adım Çizelge 5' de verilmiştir. Bu örnek, gazın çoğunun baştan başa serbestleştiği konkordant yaş ile nitelendirilen hemem hemen düz ve ideal bir yaş spektrumu vermiştir. Geleneksel K/Ar yaşına denk gelen, toplam gaz yaşı $89 . \pm 2.1$ My dir. Birinci ve dokuzuncu adımlar arasında (\%95 ${ }^{39} \mathrm{Ar}$ serbestleşmiştir) genç plato yaşı $76.6 \pm 2.2$ My olarak tanımlanmıştır (Şekil 17). Tüm 12 adım, ilksel ${ }^{40} \mathrm{Ar} /{ }^{36} \mathrm{Ar}$ oranının $304.2 \pm 2.5$ olduğu çok az miktarda artık argonun olduğunu göstermektedir ve $75.3 \pm 0.9$ My yaş ile plato yaşından ayırt edimeleyen çok iyi sınırlanmış bir izokron tanımlanmaktadır (Şekil 18). İlk ve son bir kaç adım haricinde ( toplam ${ }^{39} \mathrm{Ar}$ 'ın küçük bir yüzdesi serbestleşmiştir) $\mathrm{Ca} / \mathrm{K}$ oranları homojen alünit mineralinin gaz çıkışı (outgassing) ile uyumludur. Radyojenik ürünler $\left(\%{ }^{40} \mathrm{Ar}^{*}\right)$ bu mineral için anlamlıdır ve sistemin kristallenmeden itibaren kapalı olduğunu gösteren ideal düz bir yaş spektrumu ile uyumludur ve sonraki bir alterasyonu göstermemektedir.

SIS-1180 numaralı hornblend mineraline ait analiz sonuçları adım adım Çizelge 6'da verilmiştir. $\mathrm{Bu}$ örnek, ilk adımda yaklaşı 72 My'dan itibaren azalan, daha sonra artık gazın serbestleşmesiyle yaklaşık 80-90 My'a artan bir yaşla tanımlanan uyumsuz bir yaş spektrumu vermektedir. Toplam gaz yaşı $80.1 \pm 0.4$ My dır. Yedinci ve onuncu adımlar arasında (\% $55{ }^{39} \mathrm{Ar}$ serbestleşmiştir) plato yaşı $80.4 \pm 0.8$ My olarak belirlenmiştir (Şekil 19). Bu verilerle izokron tanımlanamamıştır. $\mathrm{Ca} / \mathrm{K}$ oranı yüksektir ve homojen olarak ayrılan hornblend mineralinden gaz çıkışı ile uyumlu olduğu gözlenmektedir. Radyojenik ürünler yüksektir ve sonraki bir alterasyonu göstermemektedir. Bu örnek için en güvenilir olarak plato yaşı kabul edilmektedir.

Çizelge 5. EVT-20/1 numaralı K-alünit mineralinde yapılan Ar-Ar yaşlandırma analizi verileri.

Table 5. Ar-Ar analytical age data of K-alunite mineral, EVT-20/1.

\begin{tabular}{|c|c|c|c|c|c|c|c|c|c|c|c|c|c|}
\hline step & $T(C)$ & $\begin{array}{c}\mathrm{t} \\
\text { (min.) }\end{array}$ & ${ }^{36} \mathrm{Ar}$ & ${ }^{37} \mathbf{A r}$ & ${ }^{38} \mathrm{Ar}$ & ${ }^{39} \mathrm{Ar}$ & ${ }^{40} \mathrm{Ar}$ & $\%^{40} \mathrm{Ar} *$ & $\begin{array}{l}\%{ }^{39} \mathrm{Ar} \\
\text { rlsd }\end{array}$ & $\mathrm{Ca} / \mathrm{K}$ & $\begin{array}{l}{ }^{40} \mathrm{Ar}^{* /} / \\
{ }^{39} \mathrm{ArK}\end{array}$ & $\begin{array}{l}\text { Age } \\
\text { (Ma) }\end{array}$ & 1s.d. \\
\hline 1 & 700 & 12 & 19,129 & 0,006 & 3,643 & 0,771 & 5553,92 & 3,1 & 1,6 & 0,357 & 225,719 & 588,57 & 289,56 \\
\hline 2 & 720 & 12 & 1,535 & 0,013 & 0,329 & 2,937 & 513,36 & 16,3 & 6,2 & 0,203 & 28,062 & 84,51 & 9,93 \\
\hline 3 & 730 & 12 & 0,769 & 0,010 & 0,228 & 5,734 & 365,33 & 41,8 & 12,2 & 0,080 & 26,447 & 79,75 & 3,79 \\
\hline 4 & 735 & 12 & 0,362 & 0,010 & 0,114 & 4,167 & 203,65 & 52,2 & 8,8 & 0,110 & 24,959 & 75,36 & 2,95 \\
\hline 5 & 740 & 12 & 0,335 & 0,010 & 0,159 & 7,379 & 281,68 & 68,5 & 15,7 & 0,062 & 25,821 & 77,91 & 2,45 \\
\hline 6 & 745 & 12 & 0,342 & 0,009 & 0,184 & 9,018 & 319,80 & 71,7 & 19,1 & 0,046 & 25,177 & 76,00 & 2,31 \\
\hline 7 & 750 & 12 & 0,309 & 0,009 & 0,153 & 7,616 & 276,57 & 70,6 & 16,2 & 0,054 & 25,310 & 76,39 & 2,37 \\
\hline 8 & 755 & 12 & 0,451 & 0,007 & 0,156 & 4,964 & 246,28 & 50,3 & 10,5 & 0,065 & 24,530 & 74,09 & 3,01 \\
\hline 9 & 760 & 12 & 0,883 & 0,011 & 0,197 & 2,012 & 299,76 & 17,8 & 4,3 & 0,251 & 26,329 & 79,40 & 8,41 \\
\hline 10 & 765 & 12 & 0,736 & 0,009 & 0,154 & 0,436 & 228,89 & 10,3 & 0,9 & 0,946 & 53,534 & 157,94 & 30,38 \\
\hline 11 & 790 & 12 & 2,827 & 0,015 & 0,564 & 1,259 & 850,04 & 6,6 & 2,7 & 0,546 & 44,737 & 132,91 & 37,13 \\
\hline 12 & 1000 & 12 & 4,084 & 0,020 & 0,824 & 0,853 & 1199,27 & 4,4 & 1,8 & 1,075 & 62,380 & 182,75 & 74,27 \\
\hline \multicolumn{9}{|c|}{ Serbest kalan toplam ${ }^{39} \mathrm{Ar}$} & 100 & \multicolumn{2}{|c|}{ Toplam gaz yaş1 } & 89,83 & 2,12 \\
\hline & & & & & & & & & & \multicolumn{2}{|c|}{ Plato yaş1 } & 76,59 & 2,19 \\
\hline & & & & & & & & & & \multicolumn{2}{|c|}{ İzokron yaş1 } & 75,30 & 0,90 \\
\hline
\end{tabular}




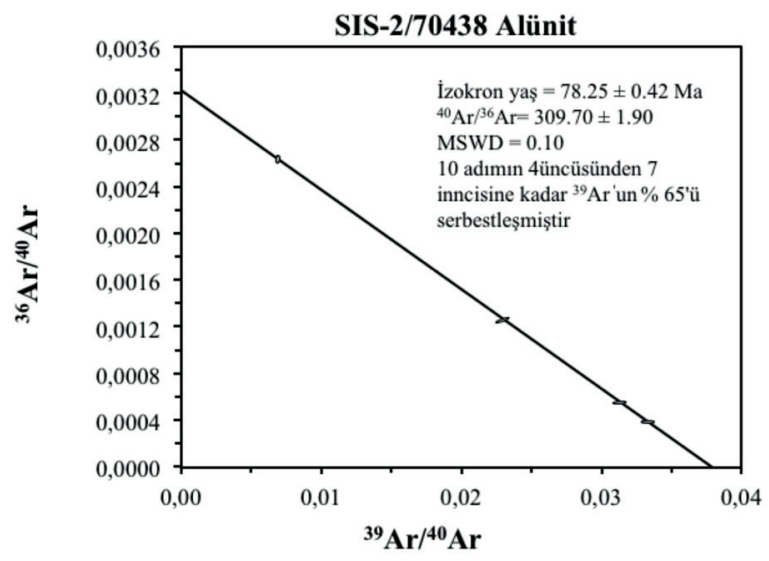

Şekil 17. EVT-20/1 numaralı K-alünit mineraline ait plato yaşını gösteren spektrum.

Figure 17. Plateau age spectrum of $K$-alunite sample, EVT-20/1.

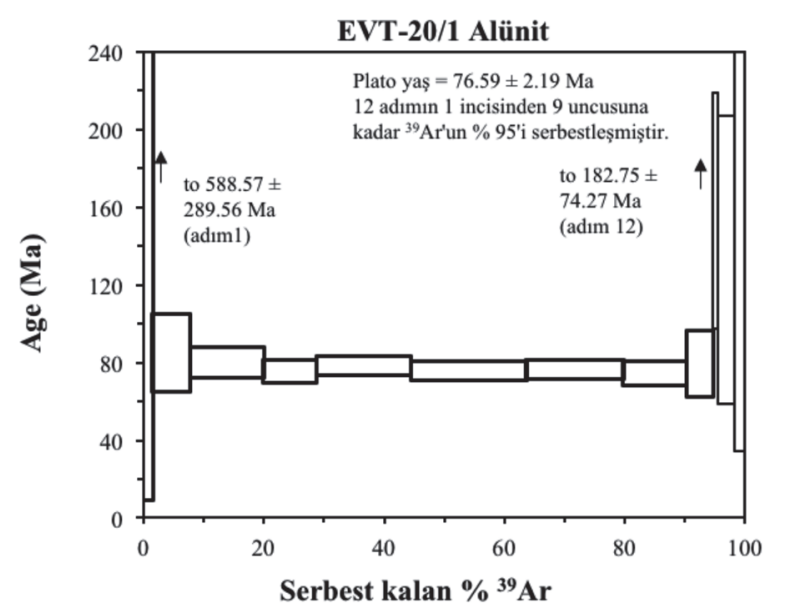

Şekil 18. EVT-20/1 numaralı K-alünit mineralinin izokron yaşını gösteren grafik.

Figure 18. Isochron age graph of $K$-alunite sample, EVT-20/1.

Çizelge 6: SIS-1180 numaralı hornblend mineralinde yapılan Ar-Ar yaşlandırma analizi verileri

Table 6: $\quad$ Ar-Ar analytical age data of hornblende mineral, SIS-1180.

\begin{tabular}{|c|c|c|c|c|c|c|c|c|c|c|c|c|c|}
\hline step & $\mathrm{T}(\mathrm{C})$ & $t$ (min.) & ${ }^{36} \mathrm{Ar}$ & ${ }^{37} \mathbf{A r}$ & ${ }^{38} \mathbf{A r}$ & ${ }^{39} \mathrm{Ar}$ & ${ }^{40} \mathrm{Ar}$ & $\%{ }^{40} A r^{*}$ & $\begin{array}{c}\%{ }^{39} \mathrm{Ar} \\
\text { rlsd }\end{array}$ & $\mathrm{Ca} / \mathrm{K}$ & $\begin{array}{l}{ }^{40} \mathrm{Ar} * / \\
{ }^{39} \mathrm{ArK}\end{array}$ & $\begin{array}{l}\text { Age } \\
\text { (Ma) }\end{array}$ & 1s.d. \\
\hline 1 & 850 & 12 & 0,397 & 0,516 & 0,316 & 3,664 & 195,35 & 45,5 & 7,5 & 5,39 & 23,923 & 71,75 & 1,06 \\
\hline 2 & 950 & 12 & 0,109 & 0,228 & 0,045 & 0,627 & 43,83 & 37,3 & 1,3 & 13,94 & 22,513 & 67,60 & 2,27 \\
\hline 3 & 1050 & 12 & 0,052 & 0,190 & 0,077 & 0,491 & 25,06 & 59,8 & 1,0 & 14,84 & 22,750 & 68,30 & 1,08 \\
\hline 4 & 1080 & 12 & 0,040 & 0,180 & 0,120 & 0,523 & 23,86 & 77,6 & 1,1 & 13,19 & 25,527 & 76,46 & 2,30 \\
\hline 5 & 1090 & 12 & 0,040 & 0,169 & 0,122 & 0,480 & 21,58 & 72,8 & 1,0 & 13,50 & 22,929 & 68,83 & 2,57 \\
\hline 6 & 1100 & 12 & 0,041 & 0,349 & 0,239 & 0,882 & 35,07 & 85,6 & 1,8 & 15,18 & 27,995 & 83,68 & 1,37 \\
\hline 7 & 1110 & 12 & 0,046 & 0,702 & 0,444 & 1,647 & 55,63 & 89,7 & 3,4 & 16,36 & 27,096 & 81,06 & 0,86 \\
\hline 8 & 1120 & 12 & 0,068 & 1,928 & 1,167 & 4,398 & 132,35 & 92,2 & 9,0 & 16,82 & 26,821 & 80,25 & 0,88 \\
\hline 9 & 1130 & 12 & 0,093 & 4,653 & 2,831 & 11,333 & 317,68 & 95,6 & 23,3 & 15,75 & 26,710 & 79,93 & 0,82 \\
\hline 10 & 1140 & 12 & 0,080 & 3,465 & 2,112 & 9,167 & 259,91 & 96,7 & 18,9 & 14,50 & 26,926 & 80,56 & 0,83 \\
\hline 11 & 1150 & 12 & 0,041 & 0,540 & 0,348 & 1,451 & 49,65 & 98,1 & 3,0 & 14,27 & 27,911 & 83,44 & 0,91 \\
\hline 12 & 1160 & 12 & 0,036 & 0,114 & 0,089 & 0,258 & 16,63 & 99,9 & 0,5 & 16,96 & 29,774 & 88,87 & 1,89 \\
\hline 13 & 1170 & 12 & 0,040 & 0,262 & 0,180 & 0,595 & 27,34 & 95,5 & 1,2 & 16,90 & 29,870 & 89,15 & 1,20 \\
\hline 14 & 1200 & 12 & 0,080 & 1,826 & 1,215 & 4,307 & 134,44 & 91,8 & 8,9 & 16,27 & 27,202 & 81,37 & 0,86 \\
\hline 15 & 1240 & 12 & 0,102 & 2,725 & 1,780 & 6,510 & 200,81 & 92,0 & 13,4 & 16,06 & 27,579 & 82,47 & 0,86 \\
\hline 16 & 1400 & 12 & 0,132 & 0,995 & 0,632 & 2,291 & 97,55 & 83,1 & 4,7 & 16,67 & 28,024 & 83,77 & 1,08 \\
\hline \multicolumn{9}{|c|}{ Serbest kalan toplam ${ }^{39} \mathrm{Ar}$} & 100 & \multicolumn{2}{|c|}{ Toplam gaz yaş1 } & 80,06 & 0,40 \\
\hline & & & & & & & & & & \multicolumn{2}{|c|}{ Plato yaş1 } & 80,44 & 0,84 \\
\hline
\end{tabular}




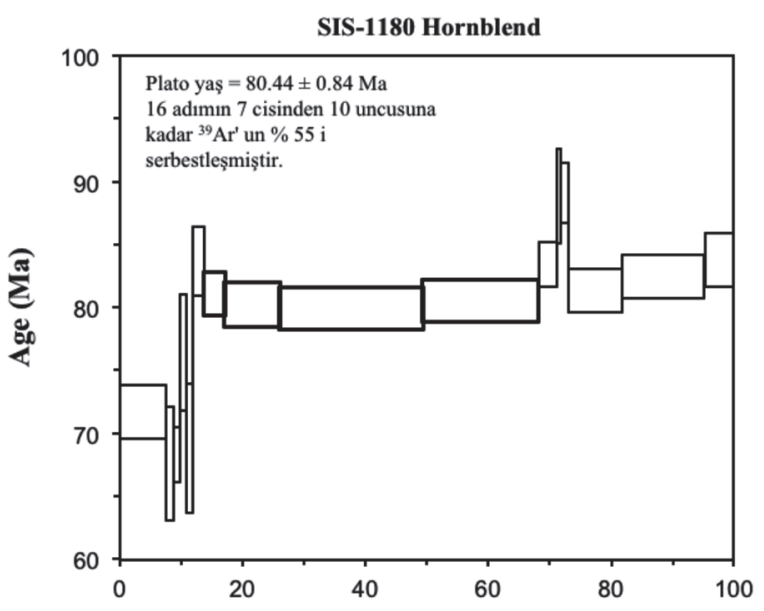

Şekil 19. SIS-1180 numaralı hornblend mineraline ait plato yaşını gösteren spektrum.

Figure 19. Plateau age spectrum of hornblende mineral, SIS-1180.

\section{TARTIŞMA ve SONUÇLAR}

İnceleme alanının tabanında Alt Kretase yaşlı andezitik aglomeralar, onları üzerleyen Üst Kretase yaşlı andezitik lavlar ve bu birimleri kesen Üst Kretase yaşlı plütonik kayaçlar yer almaktadır. Ayrıca plütonizmaya bağlı olarak gelişen ve andezitik lavların içerisinde yine Üst Kretase yaşlı olduğu düşünülen breşler yer almaktadır.

Arazi gözlemleri ve kayaç petrografisine göre (makro ve mikro ölçekteki incelemelere) inceleme alanında alterasyon belirgin şekilde gözlenmektedir. Özellikle andezitik lavlar yoğun bir şekilde altere olmuşlardır. Birimlere göre alterasyon türlerine bakıldığında;

Andezitik aglomeralarda çoğunlukla yaygın veya lokal olarak ağsı bir şekilde pirofillitik alterasyon gelişmiş ve yer yer de arjilik alterasyon gözlenmiştir.

Andezitik lavlarda, yaygın olarak arjilik alterasyon gözlenmektedir bununla beraber çok küçük bir alanda pirofillitik alterasyon belirlenmiştir. Yine andezitik bileşimli lavlarda ileri arjilik alterasyon ve silisleşme yaygın bir şekilde gözlenmektedir.

Evliya Tepe'nin zirvesinde, epitermal altın sistemi ile ilişkili olarak sert ve çok dayanımlı kuvarsca zengin silika şapka oluşmuştur. $\mathrm{Bu}$ silika şapkanın oluşumunda $\mathrm{KB}$ doğrultulu faylar boyunca çıkan çözeltiler etkin olmuştur.

İnceleme alanının güneyinde gözlenen plütonik kayaçlarda da yer yer arjilik alterasyon ve daha zayıf olarak da pirofillitik alterasyon gözlenmiştir.

Yüksek sülfidasyon epitermal yataklar için karakteristik olan boşluklu kuvarslar ileri arjilik alterasyonun çekirdeğinde gözlenmiştir.

YapılanXRD-tümkayaçanalizsonuçlarına göre, inceleme alanındaki altere kayaçlarda, bolluk sırasına göre kuvars, kil, feldispat, alünit, kalsit, hematit, götit, piroksen, hornblend, opalkristobalit mineralleri bulunmaktadır.

Cevher mikroskopisi incelemeleri sonucunda, pirit, kalkopirit, bornit, enarjit, dijenit, tennantit-tedrahedrit, kovelin, kalkosin, pirotin, sfalerit, hematit, manyetit, götit cevher mineralleri gözlenmiştir.

Pirit içerisindeki iki fazlı pirotin-kalkopirit kapanımı erken dönem düşük-orta sülfidasyon düzeyini yansıtması, porfiri sisteme olan yakınlığı belirttiği düşünülmektedir. Ayrıca tennantit-enarjit mineral birlikteliği yüksek sülfidasyon düzeyini gösterir. Pirit, enarjit, kovelin birlikteliği, enarjitin kenarlarından itibaren koveline dönüşmesi yine artan yüksek sülfidasyon düzeyine geçişi gösterir.

Cevher mineral parajenezi ve alterasyon türleri çalışma alanında tipik bir Yüksek Sülfürlü Epitermal $\mathrm{Au}-\mathrm{Cu}$ sistemini işaret etmektedir.

Sisorta altın yatağında kükürt izotop değerleri; piritlerde \%o -0,4 ile \%o -10,0 arasında, kalkopiritlerde \%o $\quad 1,5$ ile $\%$ o 2,3 arasında, 
K-alünitlerde $\% \quad 21,8$ ile $\%$ o 22,0 arasinda ve baritlerde \%o 16,2 ile \%o 18,6 arasinda değişmektedir. $\mathrm{Bu}$ sonuçlarda cevherleşmenin oluşumunda etkili olan S'ün kaynağının ilk evrelerinde hafif S izotopunun etkin olduğu daha sonraki evrelerde ise ağır S izotopunun etkin olduğu (özellikle hidrotermal evrenin son saflarında baritin oluşması sırasında) gözlenmektedir. Bu da magmatik kökenden itibaren S izotopunun değişen sıcaklıkla geliştiğini göstermektedir.

Gang minerallerinde yapilan oksijen ve döteryum analizlerine göre; kuvarslarda elde edilen $\delta^{18} \mathrm{O}$ değeri \%o 7,1 ile \%o 15,6 arasında değişirken ortalama değeri \%o 11,5 dir. K-alünitlerde elde edilen $\delta^{18} \mathrm{O}$ değeri \%o 10,1 ve \%o 11,4 dir. Naalünitlerden elde edilen $\delta^{18} \mathrm{O}$ değerleri \%o 8,5 ve \%o 12,4 tür. Kuvarslarda ölçülebilen tek $\delta \mathrm{D}$ değeri \%o -77 dir. K-alünitlerden elde edilen $\delta \mathrm{D}$ değerleri \%o -55,2 ve \%o -57,6 dir. Na-alünitlerden elde edilen $\delta \mathrm{D}$ değerleri \%o $-25,3$ ve \%o -61 'dir. $\mathrm{Bu}$ sonuçlara göre yüksek sülfürlü epitermal altın yatağının oluşumunda etkin olan çözeltinin meteorik hidrotermal kökenli sulardan itibaren ve kısmen de magmatik suyun katılımı ile geliştiği düşünülmektedir.

Yapılan ${ }^{40} \mathrm{Ar} /{ }^{39} \mathrm{Ar}$ yaş analizleri sonucunda K-alünit minerallerinde; plato yaşı $78,85 \pm 0,94$ My ve 76,59 $\pm 2,19$ My, izokron yaş $18,25 \pm 0,42$

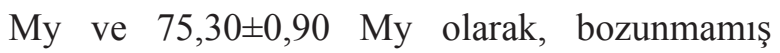
andezitik volkanik kayaçlardan ayrılan hornblend mineralinde ise plato yaş1 $80,44 \pm 0,84$ My elde edilmiştir. $\mathrm{Bu}$ sonuçlar altın cevherleşmesinde etkin olan hidrotermal alterasyonun ana kayacın yerleşiminden 3 My sonra geliştiğini göstermektedir.

Sisorta yüksek sülfidasyon altın yatağında bulunan bakır minerallerinde elde edilen $\%$ o $\delta{ }^{65} \mathrm{Cu}$ izotop değerleri -5.502 ile +3.032 arasında değişim göstermektedir. Intrüzyona (sistemin derin kısmı) yakın yerlerdeki bakır izotop değerleri önemli bir izotopsal değişim göstermemektedir $(\% \circ<1)$, bunun tersine sistemin üst kesimlerinde bakır izotop değerleri geniş bir değişim göstermekte ve buda ikincil süreçlerle bakır zenginleşmesini işaret etmektedir.

\section{KATKI BELIRTME}

Finansal desteklerden dolayı CÜBAP brimine (M-389 ve M-530 nolu projeler), saha çalışmaları sırasındaki lojistik desteklerinden dolayı Mesut SOYLU ve Cem YÜCEER'e, analitik verilerin elde edilmesindeki katkılarından dolayı; Simon POULSON, Greg B. AREHART, Mike SIM, Albert H. HOFSTRA, Terry L. SPELL, ve Ryan MATHUR'a teşekkürü borç biliriz.

\section{EXTENDED SUMMARY}

This study presents geological and geochemical features of gold deposit located in Sisorta area near Evliya Tepe, Güzelyurt village.

The investigation area covers $42 \mathrm{~km}^{2}$ land and located in $200 \mathrm{~km} \mathrm{NW}$ of Sivas province in Sisorta. The general stratigraphy of the area starts with Lower Cretaceous andesitic agglomerate and which is overlain by Upper Cretaceous andesitic lavas. All of the volcanic units intruded by Upper Cretaceous plutonic rocks. Later hydrothermal (phreatomagmatic) breccia occurred cross cuts all units and is the youngest feature.

Both silicate and sulfide minerals present are indicative of a high sulfidation epithermal gold deposit. Silicate mineral alteration occurs as propylitic, argillic, advance argillic, vugy quartz and vugy silica determined by using XRD and PIMA This silicate mineral alteration assemblage is common in high sulphidation epithermal gold deposits. Pyrite, chalcopyrite, bornite, enargite, digenite, tennantite-tetrahedrite, covellite, 
chalcocite, pyrrhotite, sphalerite, hematite, magnetite, and goethite have been defined by using ore microscopy-petrography. Tennantite-enargite mineral association, which has been observed on numerous polished sections, is good indication of high sulphidation stage.

The average REE element distribution of Cretaceous andesitic agglomerates and lavas show enrichment with compare to average values of Primitive Mantle (PM) and Cl Chondrite (C1C). Whereas, hydrothermally effected silicified andesitic volcanic rocks and hydrothermal breccia show depletion in REE element distribution with compare to average values of $P M$ and $C 1-C$.

$\delta{ }^{34} \mathrm{~S} \%$ isotope values are ranging from $-0,4$ and $\%$-10,0 in pyrites; \%o 1,5 and \%o 2,3 in chalcopyrite; 21,8 and \%o 22,0 in K-alunites; \%o 16,2 and \%o 18,6 in barites from high sulphidation epithermal gold deposits in Sisorta. At the early stage of mineralization $S$ isotope value number is light and later $S$ isotope value shows heavy numbers (specially during the formation of barite). This is indicating that the S isotope was originated from magma and changed due to temperature variations in the last stages of the hydrothermal process.

$\delta^{18} \mathrm{O}$ isotope values of gangue minerals are ranging from; \%o 7,1 to \%o 15,6 with the average value of 11,5\% in quartz, and $11,4 \%$ in $\mathrm{K}$-alunite. $\delta^{18} \mathrm{O}$ isotope data of $\mathrm{Na}$-alunite are 8,5 $\%$ and $12,4 \%$. The only quartz sample yielded $\delta D$ value of $-77 \%$. $\delta D$ value is ranging from $-55,2$ $\%$ to -57,6 in K-alunite, -25,3\%oto -61\%o in Naalunite samples. Combining $\delta^{18} O$ with $\delta D$ from quartz and K-alunite, and Na-alunite samples, demonstrates meteoric waters were important in the formation of the alteration silicate minerals analyzed. This is common in high sulfidation silicate alteration minerals.
${ }^{40} \mathrm{Ar} /{ }^{39} \mathrm{Ar}$ age dating is ranging from

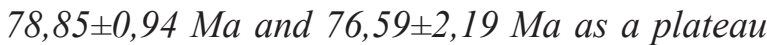

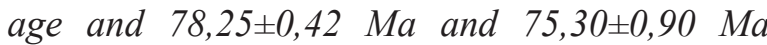
as isochron age in K-alunite, 80,44 $\pm 0,84$ in hornblende minerals from unaltered andesitic volcanic rocks. This shows that hydrothermal gold mineralization is deposited 3 Ma later than the volcanic host rock eruption.

$\delta{ }^{65} \mathrm{Cu} \%$ values from copper-bearing minerals associated with Sisorta gold deposits are ranging from $-5.502 \%$ to $+3.032 \%$. The copper isotope values closest to the intrusions (deepest part of the system) do not show significant copper isotope variations $(<1$ per mil), in contrast the upper parts of the system show large copper isotope variations and indicate enrichment of copper due to supergene processes.

According to Raman spectral data and thermometric analysis of fluid inclusions from Sisorta high sulphidation gold deposit, type of solution, which is responsible for the formation of deposit, is $\mathrm{NaCl}+\mathrm{H}_{2} \mathrm{O}$ system. $\mathrm{NaCl}$ has been defined as dissolved in liquid phase. Homogenization temperature (Th $\left.{ }_{L-1}\right)$, and wt. \% $\mathrm{NaCl}$ equivalent salinity from primary inclusions is ranging from 100 to $350{ }^{\circ} \mathrm{C}$, and from $\% 1$ to $\%$ 22 respectively.

\section{DEĞINIILEN BELGELER}

Bedi, Y., 1998, Geology of the region between Mesudiye (Ordu)-Ortakent (Koyulhisar-Sivas) and the Petrographical-Geochemical analysis of the magmatic rocks, Ph. D. Thesis, Selçuk University, $193 \mathrm{~s}$.

Braxton, D., ve Mathur, R., 2011, Exploration Applications of Copper Isotopes in the Supergene Environment: A Case Study of the Bayugo Porphyry Copper-Gold Deposit, Southern Philippines: Economic Geology, v. 106, p. 1447 1463. 
Chadwick, T., 2005, Geology of Sisorta prospect, Eurasian Minerals Inc. report.

Chambers, L.A., 1982, Sulfur isotope study of a modern intertidal environment and the interpretation of ancient sulfides. Geochim. Cosmochim. Acta, 46, 721-728.

Chaussidon, M., Albarede, F., and Sheppard, S.M.F., 1989, Sulphur isotope variations in the mantle from ion microprope analyses of micro-sulphide inclusions. Earth Planet. Sci. Lett., 92, 144-156.

Claypool, G.E., Holser, W.T., Kaplan, I.R., Sakai, H., and Zak, I., 1980, The age curves of sulfur and oxygen isotopes in marine sulfate and their mutual interpretation. Chemical Geol., 28, 199-260.

Coleman, M.L., 1977, Sulpfur isotopes in petrology. J. Geol. Soc. Lond., 133, 593-608.

Corbett, G.J., and Leach, T.M., 1988, Southwest Pasific Rim Gold-Copper Systems: Structure, Alteration, and Mineralization: SEG Special Publication, No. 6, Chapter 3, p.31-67.

Craig, H., 1961, Isotopic variations in meteoric waters. Science v. 133, p, 1702-1703.

Garofali, K., Robinson, R., Thoennessen, M., 2012, Discovery of Chromium, Manganese, Nickel, and Copper Isotopes: Atomic Data and Nuclear Data Tables, 98, p. 356-372.

Graham, S., Pearson, N., Jackson, S., Griffin, W., O'Reilly, S.Y., 2004, Tracing $\mathrm{Cu}$ and $\mathrm{Fe}$ from Source to Porphyry: in Situ Determination of $\mathrm{Cu}$ and $\mathrm{Fe}$ Isotope Ratios in Sulfides from the Grasberg Cu-Au Deposit: Chemical Geology, 207, p. 147-169.

Ikehata, K., ve Hirata, T., 2012, Copper Isotope Characteristics of Copper-Rich Minerals from the Horoman Peridotite Complex, Hokkaido, Northhern Japan: Economic Geology, v. 107, p. 1489-1497.

Jebrak, M., 1997, Hydrothermal breccias in veintype ore deposits: A review of mechanisms, morphology and size distribution: Ore Geology Reviews v.12, p. 111-134.
Kerridge, J.F., Haymon, R.M., and Kastner M., 1983, Sulfur isotope systematics at the $21 \mathrm{oN}$ site, East Pasific Rise. Earth Planet. Sci. Lett., 66, 91-100.

Larson, B.P., Maher, K., Ramos, F.C., Chang, Z., Gaspar, M., Meinert, L.D., 2003, Copper Isotope Ratios in Magmatic and Hydrothermal Oreforming Environments: Chemical Geology, 201, p. 337-350.

Lawless, J.V., White, P.J., 1990, Ore-Related Breccias: A Reviesed Genetic Classification with Particular Reference to Epithermal Deposits: 12th New Zealand Geothermal Workshop, p. 197-201.

Li, W., Jackson, S.E., Pearson, N.J, Graham, S., 2010, Copper isotopic zonation in the Northparkes porphyry $\mathrm{Cu}-\mathrm{Au}$ deposit, SE Australia: Geochimica et Cosmochimica Acta v. 74, p. 40784096.

Liu, S-A., Huang, J., Liu, J., Wörner, G., Yang, W., Tang, Y.C., Tang, L., Zheng, J., Li, S., 2015, Copper isotopic composition of the silicate Earth: Earth and Planetary Science Letters, v. 427, p.95103.

Mathur, R., Dendas, M., Titley, S., ve Phillips, A., 2010, Patterns in the Copper Isotope Composition of Minerals in Porphyry Copper Deposits in Southwestern United States, Economic Geology, 105, p. 1457-1467.

Mathur, R., Titley, S., Barra, F., Brantley, S., Wilson, M., Phillips, A., Munizaga, F., Maksaev, V., Vervoort, J., Hart, G., 2009a, Exploration Potential of $\mathrm{Cu}$ Isotope Fractionation in Porphyry Copper Deposits: Journal of Geochemical Exploration, 102, p. 1-6.

Mathur, R., Titley, S., Barra, F., Brantley, S., Wilson, M., Phillips, A., Munizaga, F., Maksaev, V., Vervoort, J., Hart, G., 2009b, Copper Isotope Fractionation Used to Identify Supergene Processes: Societyy of Economic Geologists, Special Publication 14, p. 45-49.

Mirnejad, H., Mathur, R., Einali, M., Dendas, M., ve Alirezaei, S., 2010, A Comparative Copper 
Isotope Study of Porphyry Copper Deposits in Iran: Geochemistry: Exploration, Environment, Analysis, v.10 , p. 413-418.

Ollier, C.D., 2007, Breccia-Filled Pipes: Distinguishing Between Volcanic And Non-Volcanic Origins: Geogr. Fis. Dinam. Quat. 30, p. 63-76.

Picot, P., ve Johan, Z., 1982, Atlas of Ore Minerals, Elsevier, Amsterdam, 458 pp.

Şahin Demir, Ç., 2015, Sisorta (Ortakent-KoyulhisarSivas) yöresi altın yatağının jeolojik ve jeokimyasal özellikleri: Cumhuriyet Üniversitesi Fen Bilimleri Enstitüsü, doktora tezi, 270 s, yayımlanmamış.

Sakai H., Casadevall T.J. and Moore, J.G., 1982, Chemistry and isotope ratios of sulfur in basalts and volcanic gases at Kilauea volcano, Hawaii. Geochim. Cosmochim. Acta, 46,729-738.

Sakai H., Des Maris, D.J., Ueda, A., and Moore, J.G., 1984, Concentrations and isotope ratios of carbon, nitrogen and sulfur in ocean-floor basalts and volcanic gases at Kilauea volcano, Hawaii. Geochim. Cosmochim. Acta,48, 2433-2441.

Tamaş, C.G., Milesi, J.P., 2002, Hydrovolcanic Breccia Pipe Structures - General Features And Genetic Criteria - I. Phreatomagmatic Breccias: Studia Universitatis Babeş-Bolyai, Geologia, Xlvii, 1, p. 127-147.

Tamaş, C.G., Milesi, J.P., 2003, Hydrothermal Breccia Pipe Structures - General Features And Genetic Criteria-II. Phreatic Breccias: Studia Universitatis Babeş-Bolyai, Geologia, Xlviii, 1, p. 55-66.
Taylor, J.r., H. P., 1997, Oxygenand and Hydrogen Isotope Relationships in Hydrothermal Mineral Deposits, Geochemistry of Hydrothermal Ore Deposit, 3rd Edition ed. Barnes, H.L. John Wiley \&Sons, New York, p. 229-302.

Uçurum A., Lechler, P.J., Arehart, G.B., Molnar, F., 2007, Platinum-Group Element, Stable Isotope, and Fluid Inclusion Investigation of the Ultramafic Rock-Hosted Gunes-Sogucak Ni-Cu-Sulfide Mineralization, Gunes Ophiolite, East-Central Turkey: International Geology Review, v.49, p.169-192.

Ueda, A., and Sakai, H., 1984, Sulfur isotope study of Quaternary volcanic rocks from the Japanese island arc. Geochim. Cosmochim. Acta, 48, 18371848 .

Yetkin, E., 2009, Alteration identification by hyperspectral remote sensing in Sisorta Gold Prospect (Sivas-Turkey): unpublished $\mathrm{PhD}$ thesis, Middle East Technical University, 129 p.

\begin{tabular}{ll}
\hline $\begin{array}{l}\text { Makale Geliş Tarihi } \\
\text { Kabul Tarihi }\end{array}$ & $:$ 11 Aralık 2015 \\
& $: 8$ Ocak 2016 \\
Received & $: 11$ December 2015 \\
Accepted & $:$ 8 January 2016
\end{tabular}

